\title{
Caracterização pedológica de locais de estudo de populações naturais de castanheira-do-brasil no estado de Mato Grosso
}

\author{
Silvio Tulio SPERA ${ }^{1 *}$, Ciro Augusto de Souza MAGALHÃES ${ }^{1}$, Aisy Botega BALDONI ${ }^{1}$, \\ Sebastiao Barreiros CALDERANO ${ }^{2}$ \\ ${ }^{1}$ Embrapa Agrossilvipastoril, Sinop, MT, Brasil. \\ ${ }^{1}$ Embrapa Solos, Rio de Janeiro, RJ, Brasil. \\ *E-mail: silvio.spera@embrapa.br
}

Recebido em abril/2018; Aceito em outubro/2018.

\begin{abstract}
RESUMO: A castanheira-do-brasil (Bertholletia excelsa Bonpl.) é nativa da Amazônia e importante espécie de exploração extrativista. $\mathrm{O}$ ambiente edáfico característico de áreas de ocorrência de concentração de populações naturais de castanheira-do-brasil, no norte de Mato Grosso foi avaliado. O estudo foi conduzido em quatro áreas de ocorrência de castanhais no norte de Mato Grosso, nos municípios de Itaúba, Alta Floresta, Juína e Cotriguaçu, nos quais se descreveu os perfis de solos, e dos quais foram feitas análises químicas, granulométricas e mineralógicas. Os resultados indicaram que a castanheira-do-brasil é espécie típica de clima predominante na Amazônia, que ocorre em solos ácidos, de textura variando de arenosa a média, de baixa fertilidade natural e, às vezes, com elevado teor de alumínio, entretanto, são solos cauliníticos ou cauliníticos-gibbsíticos, o que os difere da maioria dos solos de cerrados. Foram identificados solos dos grandes grupos Argissolo Vermelho Amarelo distróficos e Latossolo Vermelho Amarelo distróficos de relevo plano a ondulado.
\end{abstract}

Palavras-chave: solos florestais, perfil de solo, atributos químicos, pedomorfologia, mineralogia.

\section{Pedological characterization at places of occurrence of natural populations of Brazil nuts in the State of Mato Grosso}

\begin{abstract}
The Brazil nuts trees (Bertholletia excels Bonpl.) are native to the Amazon and important specie of extractive exploitation. The edaphic environment characteristic of concentration areas of Brazil nuts tree specimens, in the North of Mato Grosso was evaluated in research project that studied the edaphic attributes at places of occurrence of natural populations of Brazil nuts in the State of Mato Grosso. The study was carried out in four areas of Brazil nuts occurrence in the North of Mato Grosso, in the municipalities of Itaúba, Alta Floresta, Juína and Cotriguaçu, which described the soil profiles, and which were made chemical, physical and mineralogical analysis. The results indicated that the Brazil nuts tree is a typical specie of the Amazon, which grows in the State of Mato Grosso, in soils acids, ranging from sandy to loamy texture, low natural fertility and, sometimes, with high content of aluminum, however, is a caullinitic or caullinitic-gibbsitic soils, which differs from the majority of soils of the Brazilian savanna. Soils were identified as dystrophic Red Yellow Argisols (Haplustult) and Red Yellow Latosols (Haplustox) and relief vary from plain to undulate.

Keywords: forest soils, soil profile, chemical attributes, morphological attributes, mineralogy.
\end{abstract}

\section{INTRODUÇÃO}

A castanheira-do-brasil (Bertholletia excelsa Bonpl.), nacionalmente conhecida como castanheira-do-pará, é considerada uma das mais importantes espécies de exploração extrativista, sendo que a semente tem alto valor nutricional e comercial, os frutos são utilizados em artesanato, e a madeira pode ser empregada na construção civil, apesar do seu corte ser proibido (SALOMÃO et al., 2006). A devastação dos castanhais nativos, devido ao avanço das fronteiras agrícolas e das queimadas, representa uma ameaça à espécie. Assim, para que a castanheira seja explorada de forma sustentável, é importante avaliar a diversidade e a estrutura genética populacional dos maciços florestais da espécie. Estudos como esses orientarão ações de preservação da espécie in situ, garantindo a sustentabilidade dessa atividade agrícola. Além disso, o conhecimento da diversidade genética existente gerará informações importantes para futuros trabalhos, desde a orientação de ações para a criação de um banco de germoplasma, bem como criar estratégias para programas de melhoramento genético com a espécie e estimular seu plantio comercial, especialmente em sistemas agrossilvipastoris.

A castanheira-do-brasil ocorre em terras firmes de mata alta, quase sempre em locais de difícil acesso, com dispersão natural abrangendo desde o alto Orinoco $\left(5^{\circ}\right.$ latitude $\left.\mathrm{N}\right)$ até $\mathrm{o}$ alto Beni (14 latitude S), onde estão inclusas a Venezuela, Colômbia, Peru, Bolívia e Guianas, no entanto, as mais numerosas formações compactas desta espécie estão em terras brasileiras, localizadas nos estados do Pará (rios Trombetas, Tapajós, Xingu, Tocantins e afluentes), Maranhão (área constituinte da Amazônia Legal), Mato Grosso (rios Araguaia e Teles Pires), Amazonas (rios Amazonas, Madeira, Negro. Purus e afluentes) e Acre (rios Purus. Acre, laco e Abunã) (SALOMÃO et al., 2006).

O ambiente edáfico de ocorrência da castanheira-do-brasil geralmente foi descrito no passado como preferencial o solo argiloso ou argilo-silicoso (MULLER et al., 1980). Entretanto, 
Scoles et al. (2011) destaca que as condições de luminosidade são as determinantes. Os autores destacam a ocorrência da castanheira em Argissolos Vermelho Amarelos e Latossolos Vermelho Amarelos, no entanto, não descrevem a textura ou outras características morfológicas destes solos.

De acordo com Costa et al. (2017), as árvores com maior produção de frutos ocorrem em solo com maior teor de $\mathrm{Al}$ trocável na camada de $0-20 \mathrm{~cm}$, bem como com menor valor de $\mathrm{pH}$ e saturação por bases. E reportaram que que árvores mais produtivas de castanheira contribuem na remoção de bases trocáveis, favorecendo a acidificação do solo. Entretanto, a castanheira-do-brasil mostrou-se extratora de cálcio, os autores evidenciaram a importância do manejo visando a reposição do nutriente, como, por exemplo, a restituição ao solo dos resíduos de poda e das cascas das amêndoas e dos ouriços da castanheira (KLUCZKOVSKI et al., 2015).

A mineralogia dos solos da Amazônia é caracterizada pela natureza do material de origem. Áreas mais extensas de solos eutróficos só existem onde há influência atual (planície aluvial) ou pretérita (terraços e baixos planaltos das bacias do Acre e do Alto Amazonas) de sedimentos andinos; ou, ainda, onde afloram rochas de maior riqueza em bases (calcários e margas; basaltos e diabásios). De modo geral, nas demais áreas, as condições bioclimáticas atuais, as características do material de origem e o relevo levam à formação de solos profundos e muito intemperizados (SCHAEFFER et al., 2008). Predominam, portanto, minerais silicatados intemperizados do grupo das caulinitas e óxidos de ferro e alumínio (LIMA et al, 2006).

Em 2012 um projeto de pesquisa da Embrapa Acre propôs o estudo da diversidade, estruturação genética espacial intrapopulacional, sistema de reprodução e padrões de dispersão de sementes e pólen em populações naturais localizadas nos estados do Acre e de Mato Grosso. Para estudar a diversidade morfológica e físico-química, intra e interpopulacional das castanheiras os aspectos abióticos, como variáveis de atributos químicos, físicos e morfo-estruturais do solo foram monitorados nos solos das populações de castanheira-do-brasil avaliadas. Essas informações são úteis para orientar práticas de manejo, bem como embasar futuros trabalhos taxonômicos, filogenéticos e ecológicos com a espécie.

Os resultados gerados neste estudo serão úteis para nortear ações, que vão desde iniciativas de preservação da castanheira no habitat natural, coleta de sementes para programas de conservação ex situ, estudos filogenéticos com a espécie, melhoramento florestal e recuperação ambiental, bem como informações visando sua exploração sustentável, como mais uma alternativa para a agricultura brasileira.

As informações sobre a variabilidade edáfica do solo em quatro populações de castanheira-do-brasil de Mato Grosso e suas relações com os indicadores morfológicos e físicoquímicos dos indivíduos analisados são escassas, não permitindo, muitas vezes, orientar futuras estratégias de preservação da espécie para garantir sua exploração econômica e sustentável.

Além disso, os dados obtidos foram correlacionados com os indicadores morfológicos e físico-químicos dos indivíduos analisados, já que foram encontradas diferenças, principalmente na morfologia dos frutos de castanha, de acordo com a região onde se encontra o maciço.

\section{MATERIAL E MÉTODOS}

2.1. Caracterização pedológica do solo

As características morfo-pedológicas do solo das áreas de castanheira-do-brasil foram avaliadas mediante a descrição pedológica de perfis de solos das cinco áreas de estudo, conforme Santos et al. (2013) e a identificação das classes de solo foi feita conforme Embrapa (2013) e com auxílio da carta de cores de Munsell (1994).

Nas áreas das quatro populações de castanheira-do-brasil no estado de Mato Grosso (Figura 1), os solos foram caracterizados mediante descrição de perfis de solos em trincheiras.

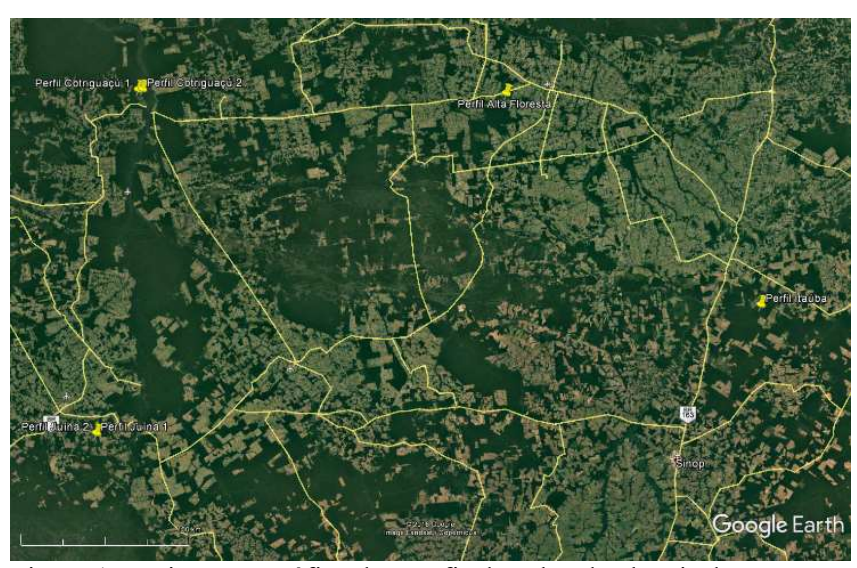

Figura 1. Posição geográfica dos perfis de solos dos locais das quatro populações de castanheira-do-brasil, no estado de Mato Grosso. Imagem: Google Earth, 2018.

Figure 1. Geographical position of the soil profiles locations of the four populations of Brazil nuts trees in the State of Mato Grosso. Image: Google Earth, 2018.

$\mathrm{Na}$ caracterização física dos perfis foram analisados: areia, silte, argila, enquanto que na caracterização química: $\mathrm{pH}$ em água, fósforo, potássio, cálcio, magnésio, acidez trocável $\left(\mathrm{Al}^{3+}\right)$, acidez potencial $(\mathrm{H}+\mathrm{Al})$, carbono orgânico. Os métodos utilizados foram: $\mathrm{P}$ e K, Mehlich-1; $\mathrm{Ca}, \mathrm{Mg}$ e $\mathrm{Al}: \mathrm{KCl}$ $1 \mathrm{~mol} \mathrm{~L}{ }^{-1} ; \mathrm{H}+\mathrm{Al}$ : acetato de cálcio $0,5 \mathrm{~mol} \mathrm{~L}^{-1}$ a pH 7,0; matéria orgânica do solo: Walkley e Black, conforme Silva (2009).

Os teores de $\mathrm{SiO}_{2}, \mathrm{Al}_{2} \mathrm{O}_{3}, \mathrm{Fe}_{2} \mathrm{O}_{3} \quad \mathrm{eTiO}_{2}$, e as relações moleculares: $\mathrm{SiO}_{2} / \mathrm{Al}_{2} \mathrm{O}_{3}(\mathrm{Ki}), \mathrm{SiO}_{2} / \mathrm{R}_{2} \mathrm{O}_{3}(\mathrm{Kr})$ e $\mathrm{Al}_{2} \mathrm{O}_{3} / \mathrm{Fe}_{2} \mathrm{O}_{3}$ foram obtidos após ataque sulfúrico das amostras, conforme Donagemma et al. (2011). A identificação da litologia, da formação geológica e do material originário foi feita conforme SEPLAN-MT (2011).

\subsection{Caracterização mineralógica do solo}

A fração argila $(\varnothing<0,002 \mathrm{~mm})$ foi separada no laboratório de Física da Embrapa Solos, conforme Donagemma et al. (2011). As amostras foram analisadas em condição "ao natural" e sob os seguintes tratamentos: desferrificação por DCB (ditionito-citrato-bicarbonato de sódio), de acordo com Mehra; Jackson (1960); saturação com potássio e aquecimento por duas horas, após montagem da lâmina, nas temperaturas: $110^{\circ}, 350^{\circ}$ e $550^{\circ}$; saturação com $\mathrm{Mg}$ e solvatação com etileno glicol, conforme Donagemma et al. (2011) e Calderano et. al. (2009). As lâminas foram preparadas de forma orientada, pelo método do esfregaço. Foi usado o aparelho difratômetro Rigaku, modelo: Miniflex II, radiação: $\mathrm{Cu} \mathrm{K \alpha} \ldots \lambda=0,154 \mathrm{~nm}$. 
Os difratogramas foram confeccionados usando 0 programa Microcal Origin 6.0 e foram apresentados na seguinte ordem: amostra não tratada (Am.total); amostra desferrificada e saturada com magnésio $(\mathrm{Mg})$ e posteriormente solvatada com etileno glicol (MgEG); amostra desferrificada e saturada com potássio, com leituras executadas à temperatura ambiente (K25) e, após aquecimento, nas temperaturas assinaladas (K110, K350 e K550). A interpretação dos difratogramas foi feita com base nas tabelas da base de dados do JCPDS-ICDD (ICDD, 2016). A grafia dos nomes dos minerais está de acordo com Branco (1987).

\section{RESULTADOS}

3.1. Caracterização morfo-pedológica dos solos

\subsubsection{Ambiente edáfico das áreas de ocorrência da castanheira-do-brasil}

A descrição geral dos perfis de solo das áreas de castanhais nativos, bem como as características morfológicas, granulometria, atributos químicos e mineralógicos estão relacionados a seguir e apresentados nas tabelas 1, 2, 3, 4, 5, $6,7,8,9,10,11$ e 12. Na Figura 1 pode-se observar a localização geográfica dos quatro locais com perfis descritos nesse trabalho. Nas Figuras 2 e 3 estão ilustradas imagens de Latossolo e Argissolo Vermelho Amarelos Distróficos, provenientes das áreas de concentração de castanheiras-dobrasil no norte de Mato Grosso.

\subsubsection{Descrições gerais e classificação dos perfis de solos estudados}

\section{Perfil n $n^{\circ} 1$ (Itaúba)}

Classificação: LATOSSOLO VERMELHO AMARELO Distrófico típico, A moderado, textura média, floresta equatorial subperenifólia, relevo plano.

Localização, município e estado: município de Itaúba/MT. Coordenadas $11^{\circ} 06^{\prime} 05.99^{\prime}$ 'S e $55^{\circ} 01^{\prime} 48.73^{\prime}$ 'W.

Situação, declive e cobertura vegetal sobre o perfil: trincheira aberta em área de mata fechada, em posição nivelada do terreno.

Altitude: $384 \mathrm{~m}$

Litologia e formação geológica: Pré-Cambriano Médio, Formação Dardanelos.

Material originário: Sedimentos areno-argilosos.

Pedregosidade: Ausente.

Rochosidade: Ausente.

Relevo local: Plano.

Relevo regional: Plano a suave-ondulado.

Erosão: não aparente.

Drenagem: acentuadamente drenado.

Vegetação primária: floresta equatorial subperenifólia com castanheiras (Bertholetia excelsa), sob ação antrópica.

Uso atual: exploração extrativa de castanha-do-brasil.

Data da descrição: 17/02/2013.

Descrito e coletado por: Silvio Tulio Spera e Bruno Eduardo Begrow.
Descrição morfológica

Oo: -2 - $-1 \mathrm{~cm}$; material orgânico pouco decomposto, facilmente reconhecíveis.

Ooo: -1 - $0 \mathrm{~cm}$; material orgânico decomposto, não discerníveis.

A1: 0 - $3 \mathrm{~cm}$; bruno-avermelhado escuro (4,0 YR 4/3 úmido); areia franca, moderada granular pequena e média e fracos blocos subangulares muito pequenos e pequenos, não pegajosa, ligeiramente plástico, muito friável, macia, abundantes poros muito pequenos e pequenos, comuns médios e poucos grandes; muitas raízes pivotantes finas, transição clara e plana.

A2: 3 - $15 \mathrm{~cm}$; bruno-avermelhado escuro (4,0 YR 4/4 úmido); franco-arenosa, moderada, granular pequena e média e fracos blocos subangulares muito pequenos e pequenos, ligeiramente pegajoso, ligeiramente plástico, muito friável, macia, abundantes poros muito pequenos e pequenos, comuns médios e poucos grandes; muitas raízes pivotantes finas, transição gradual e plana.

AB: 15 - $36 \mathrm{~cm}$; bruno-avermelhado (4,0 YR 4/5 úmido); franco-argilo arenosa, moderada, granular muito pequena a média e fracos blocos subangulares muito pequenos e pequenos, ligeiramente pegajoso, plástico, friável, macia, abundantes poros muito pequenos e pequenos, comuns médios e raros grandes; muitas raízes pivotantes finas, médias e grossas, transição gradual e plana.

BA: 36 - $50 \mathrm{~cm}$; bruno-avermelhado (4,0 YR 4/6 úmido); franco-argilo arenosa, moderada, granular muito pequena a média e fracos blocos subangulares muito pequenos e pequenos, ligeiramente pegajoso, plástico, friável, macia, abundantes poros muito pequenos, muitas raízes pivotantes finas, médias e grossas, transição gradual e plana.

Bw1: 50 - $88 \mathrm{~cm}$; bruno-avermelhado (3,5 YR 4/6 úmido); franco-argilo arenosa, moderada, granular muito pequena a média, pegajoso, muito plástico, friável, macia, abundantes poros muito pequenos, muitas raízes lenhosas grossas (diâmetro de 7 a $12 \mathrm{~cm}$ ), transição difusa e plana.

Bw2: 88 - $170 \mathrm{~cm}$; bruno-avermelhado (3,5 YR 4/7 úmido); franco-argilo arenosa, moderada, granular muito pequena a média, pegajoso, muito plástico, muito friável, macia, abundantes poros muito pequenos, comuns raízes lenhosas médias (diâmetro de 3 a $5 \mathrm{~cm}$ ), transição difusa e plana.

Bw3: 170 - 210 cm; bruno-avermelhado (3,5 YR 4/7 úmido); franco-argilo arenosa, moderada, granular muito pequena, ligeiramente pegajoso, plástico, muito friável, macia, abundantes poros muito pequenos, poucas raízes lenhosas médias (diâmetro de 3 a $5 \mathrm{~cm}$ ) (coletado com trado).

Bw4: 210 - $290 \mathrm{~cm}$; bruno-avermelhado (3,5 YR 4/7 úmido); franco-argilo arenosa, moderada, granular muito pequena, pegajoso, plástico, muito friável, macia, poucas raízes lenhosas médias (coletado com trado).

Bw5: $290 \mathrm{~cm}$ +; bruno-avermelhado (3,5 YR 4/8 úmido); argilo-arenosa, moderada, granular muito pequena, pouco pegajoso, plástico, friável, macia (coletado com trado). 
Análises físicas e químicas

Tabela 1. Granulometria e densidade do solo das camadas amostradas em perfil do castanhal da área de Itaúba-MT.

Table 1. Particle size and soil density samples of layers of a soil profile in area of Brazil-nuts occurrence, Itaúba-MT.

\begin{tabular}{|c|c|c|c|c|c|c|}
\hline \multirow{2}{*}{ 胥 } & Espessura & Argila & $\begin{array}{l}\text { Silte } \\
\text { (S) }\end{array}$ & $\begin{array}{c}\text { Areia } \\
\text { (A) }\end{array}$ & $\begin{array}{c}\text { Relação } \\
\text { S/A }\end{array}$ & Ds \\
\hline & $\mathrm{cm}$ & ------. & $-\mathrm{g} \mathrm{kg}$ & ----- & - & $\mathrm{kg} \mathrm{dm}_{3}^{-}$ \\
\hline A1 & $0-3$ & 133 & 30 & 837 & 0,23 & 1,02 \\
\hline A2 & $3-15$ & 149 & 24 & 827 & 0,16 & 1,13 \\
\hline $\mathrm{AB}$ & $15-36$ & 226 & 32 & 742 & 0,14 & 1,24 \\
\hline BA & $36-50$ & 213 & 40 & 747 & 0,19 & 1,23 \\
\hline Bw1 & $50-88$ & 232 & 55 & 713 & 0,24 & 1,11 \\
\hline Bw2 & $88-170$ & 227 & 59 & 714 & 0,26 & 1,09 \\
\hline Bw3 & $170-210$ & 241 & 30 & 729 & 0,12 & 1,00 \\
\hline Bw4 & $210-290+$ & 249 & 41 & 710 & 0,16 & 0,98 \\
\hline
\end{tabular}

Dados: Embrapa Agrossilvipastoril (2015). Data: Embrapa Agrossilvipastori (2015).

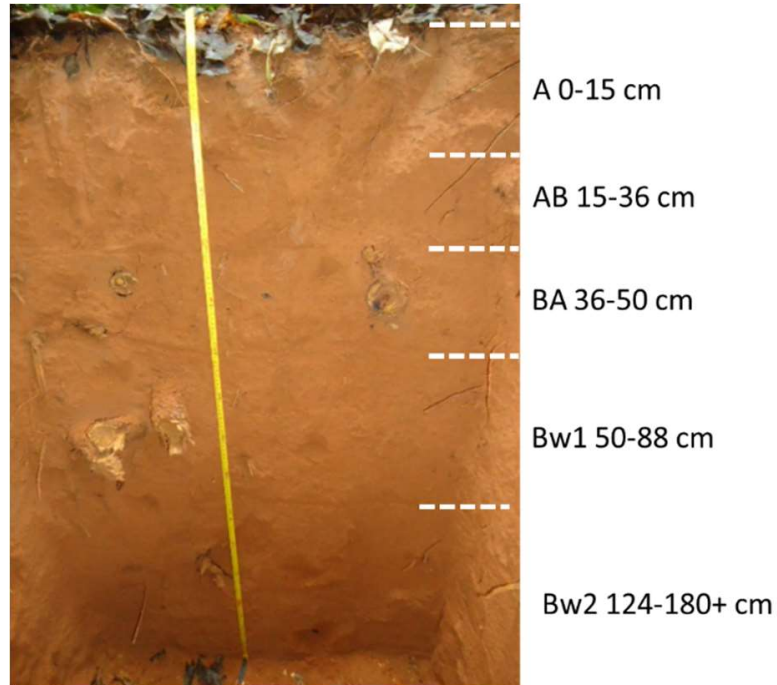

Figura 2. Perfil de Latossolo Vermelho Amarelo distrófico de ItaúbaMT. As camadas Bw3, Bw4 e Bw5 foram coletadas com trado. Foto: Spera, S.T. (2013).

Figure 2. Profile of a Dystrophic Red Yellow Latosol of Itaúba-MT. The layers Bw3, Bw4 and Bw5 were collected with auger. Photo: Spera, S.T. (2013).

Tabela 2. Resultados analíticos químicos das camadas amostradas em perfil do castanhal da área de Itaúba-MT.

Table 2. Chemical analytical results of sampled layers of a soil profile of an area of Brazil-nuts occurrence, Itaúba-MT.

\begin{tabular}{|c|c|c|c|c|c|c|c|c|c|}
\hline \multirow[b]{2}{*}{ Camada } & $\mathrm{pH}$ & $\mathrm{Ca}^{2+}$ & $\mathrm{Mg}^{2+}$ & $\mathrm{K}^{+}$ & $\mathrm{Al}^{3+}$ & $\mathrm{T}$ & $\mathrm{P}$ & V & $\mathrm{m}$ \\
\hline & água & \multicolumn{4}{|c|}{$\mathrm{cmol}_{\mathrm{c}} \mathrm{dm}^{-3}$} & \multicolumn{2}{|c|}{$\mathrm{mg} \mathrm{dm}^{-3}$} & \multicolumn{2}{|c|}{$\%$} \\
\hline A1 & 4,5 & 0,3 & 0,1 & 0,07 & 0,6 & 6,4 & 5 & 8 & 55 \\
\hline A2 & 4,5 & 0,3 & 0,1 & 0,06 & 0,5 & 6,4 & 4 & 9 & 45 \\
\hline $\mathrm{AB}$ & 5,3 & 0,4 & 0,2 & 0,08 & 0,1 & 3,7 & $<1$ & 19 & 12 \\
\hline BA & 4,5 & 0,3 & 0,1 & 0,03 & 0,3 & 3,7 & $<1$ & 11 & 43 \\
\hline Bw1 & 4,1 & 0,2 & 0,1 & 0,01 & 0,4 & 2,8 & $<1$ & 11 & 57 \\
\hline Bw2 & 5,1 & 0,2 & 0,1 & 0,03 & 0,1 & 2,1 & $<1$ & 19 & 20 \\
\hline Bw3 & 4,9 & 0,3 & 0,1 & 0,01 & 0 & 1,6 & $<1$ & 25 & 0 \\
\hline Bw4 & 4,7 & 0,2 & 0,1 & 0,02 & 0 & 1,8 & $<1$ & 17 & 0 \\
\hline \multirow[t]{2}{*}{ Camada } & $\mathrm{C}_{\text {org }}$ & $\mathrm{N}_{\text {totlal }}$ & \multicolumn{4}{|c|}{ Ataque sulfúrico } & \multicolumn{3}{|c|}{ Relações moleculares } \\
\hline & $\mathrm{g} \mathrm{kg}^{-1}$ & & $\mathrm{SiO}_{2}$ & $\mathrm{Al}_{2} \mathrm{O}_{3}$ & $\mathrm{Fe}_{2} \mathrm{O}_{3}$ & $\mathrm{TiO}_{2}$ & $\mathrm{SiO}_{2} / \mathrm{Al}_{2} \mathrm{O}_{3} \mathrm{Ki}$ & $\mathrm{SiO}_{2} / \mathrm{R}_{2} \mathrm{O}_{3} \mathrm{Kr}$ & $\mathrm{Al}_{2} \mathrm{O}_{3} / \mathrm{Fe}_{2} \mathrm{O}_{3}$ \\
\hline A1 & 12,2 & 1,1 & & & & & & & \\
\hline A2 & 8,2 & 1 & & & & & & & \\
\hline $\mathrm{AB}$ & 4,6 & 0,6 & & & & & & & \\
\hline BA & 3,6 & 0,6 & & & & & & & \\
\hline Bw1 & 3,3 & 0,5 & 40 & 87 & 32 & 4,4 & 0,78 & 0,63 & 4,27 \\
\hline Bw2 & 1,7 & 0,3 & & & & & & & \\
\hline Bw3 & 0,8 & 0,2 & & & & & & & \\
\hline Bw4 & 2,4 & 0,3 & & & & & & & \\
\hline
\end{tabular}

Dados: Embrapa Agrossilvipastoril (2015). Data: Embrapa Agrossilvipastoril (2015).

\section{Perfil n 1 Juina}

Classificação: PLINTOSSOLO ARGILÚVICO Distrófico arênico, textura areia/areia franca, A moderado, relevo suaveondulado, floresta tropical subperenifólia.

Localização, município e estado: coordenadas 11³6’39.31" S e 58³6’42.36" W, município de Juína/MT, Faz. LusoBrasileira.

Situação, declive e cobertura vegetal sobre o perfil: trincheira aberta em área de mata ciliar alterada pelo uso com pastagem, no terço inferior da vertente curta.

Altitude: $295 \mathrm{~m}$

Litologia e formação geológica: Cretáceo, Formação Utiariti

Material originário: sedimentos argilo-arenosos com concreções.

Pedregosidade: Ausente.

Rochosidade: Ausente.

Relevo local: suave ondulado.
Relevo regional: Plano a suave-ondulado.

Erosão: Erosão em sulcos causa pelo gado.

Drenagem: Imperfeitamente drenado.

Vegetação primária: floresta equatorial subperenifólia, sob ação antrópica.

Uso atual: área de exploração com gado e castanheiras.

Descrito e coletado por: Silvio Tulio Spera e Nilton César Morel.

Data da descrição: 26/06/2014.

Observações: Coletado em trincheira escavada em barranco baixo, entre mata ciliar e pastagem de Brachiaria.

Descrição morfológica

A1: $0-8 \mathrm{~cm}$; cinza brunado (5 YR 5/1 seco), brunoacinzentado (5 YR 5/2 úmido); areia; fraca, grãos simples, granular pequena e blocos subangulares pequenos e médios q.s.d em grãos simples, solta, muito friável, não plástico e não 
pegajoso; muitos poros muitos pequenos, pequenos, médios e comuns grandes; abundantes raízes muito finas, finas e médias; transição plana e clara.

A2: 8 - $22 \mathrm{~cm}$; bruno-acinzentado (5 YR 5/2 seco), brunoacinzentado (5 YR 5/2 úmido); areia; fraca, grãos simples, granular pequena e blocos subangulares pequenos e médios q.s.d em grãos simples, solta, muito friável, não plástico e ligeiramente pegajoso; muitos poros muitos pequenos, pequenos, médios e comuns grandes; abundantes raízes muito finas, finas e médias; transição plana e abrupta.

Bt1: 22 - $70 \mathrm{~cm}$; bruno-avermelhado-claro (5 YR 5/4 úmido); areia franca; fraca, blocos subangulares pequeno e médio; macia, friável, ligeiramente plástico e ligeiramente pegajoso; cerosidade comum fraca, poros comuns muito pequenos e pequenos, raros médios; raízes comuns muito finas; transição plana e gradual.

Bt2: 70 - $100 \mathrm{~cm}+$; bruno-avermelhado (5 YR 5/5 úmido); areia franca; moderada, blocos subangulares pequeno e médio; macia, friável, ligeiramente plástico e ligeiramente pegajoso; cerosidade comum fraca, poros comuns muito pequenos e pequenos, raros médios; raízes poucas muito finas; transição plana e gradual.

Lençol freático a $1,0 \mathrm{~m}$ de profundidade. Castanheiras ausentes. Bt2: mosqueado pouco 5 YR 5/6 (brunoavermelhado escuro).

\section{Análises físicas e químicas}

Tabela 3. Granulometria das camadas do perfil $n^{\circ} 1$ do castanhal da área de Juína-MT

Table3. Particle size of the layers of the profile nr. 1 of sampled in a soil profile of an area of Brazil-nuts occurrence, Juína-MT

\begin{tabular}{cccccc}
\hline \multirow{2}{*}{ Camada } & $\begin{array}{c}\text { Espessur } \\
\mathrm{a}\end{array}$ & Argila & $\begin{array}{c}\text { Silte } \\
(\mathrm{S})\end{array}$ & $\begin{array}{c}\text { Areia } \\
(\mathrm{A})\end{array}$ & Relação S/A \\
\cline { 3 - 6 } & $\mathrm{cm}$ & $-------------\mathrm{g} \mathrm{kg}^{-1}$ & -------- & \\
\hline A1 & $0-8$ & 60 & 56 & 884 & 0,93 \\
$\mathrm{~A} 2$ & $8-22$ & 60 & 72 & 868 & 1,20 \\
$\mathrm{Bt} 1$ & $22-70$ & 80 & 94 & 826 & 1,17 \\
$\mathrm{Bt} 2$ & $70-100+$ & 100 & 66 & 834 & 0,66 \\
\hline
\end{tabular}

Dados: Embrapa Agrossilvipastoril (2015). Data: Embrapa

Agrossilvipastoril (2015).

Tabela 4. Resultados analíticos químicos das camadas do perfil $\mathrm{n}^{\circ} 1$ do castanhal da área de Juína-MT.

Table 4. Chemical analytical results of sampled layers of the profile nr. 1 of sampled in a soil profile of an area of Brazil-nuts occurrence, Juína-MT.

\begin{tabular}{|c|c|c|c|c|c|c|c|c|c|}
\hline \multirow{2}{*}{ Camada } & $\mathrm{pH}$ & $\mathrm{Ca}^{2+}$ & $\mathrm{Mg}^{2+}$ & $\mathrm{K}^{+}$ & $\mathrm{Al}^{3+}$ & $\mathrm{T}$ & $\mathrm{P}$ & $\mathrm{V}$ & $\mathrm{m}$ \\
\hline & água & \multicolumn{4}{|c|}{$\mathrm{cmol}_{\mathrm{c}} \mathrm{dm}^{-3}$} & \multicolumn{2}{|c|}{$\mathrm{mg} \mathrm{dm^{-3 }}$} & \multicolumn{2}{|c|}{$\%$} \\
\hline A1 & - & 0,3 & - & 0,04 & 0,7 & 5,7 & 25 & 5 & 70 \\
\hline $\mathrm{A} 2$ & - & 0,1 & - & 0,02 & 0,6 & 4,1 & 1 & 2 & 86 \\
\hline Bt1 & - & 0,1 & - & 0,01 & 0,5 & 3,6 & 1 & 3 & 83 \\
\hline $\mathrm{Bt} 2$ & - & 0,1 & - & 0,01 & 0,4 & 2,7 & 1 & 4 & 80 \\
\hline \multirow[t]{2}{*}{ Camada } & $\mathrm{C}_{\text {org }}$ & $\mathrm{N}_{\text {total }}$ & \multicolumn{4}{|c|}{ Ataque sulfúrico } & \multicolumn{3}{|c|}{ Relações moleculares } \\
\hline & $\mathrm{g} \mathrm{kg}^{-1}$ & & $\mathrm{SiO}_{2}$ & $\mathrm{Al}_{2} \mathrm{O}_{3}$ & $\mathrm{Fe}_{2} \mathrm{O}_{3}$ & $\mathrm{TiO}_{2}$ & $\mathrm{SiO}_{2} / \mathrm{Al} 2 \mathrm{O} 3 \mathrm{Ki}$ & $\mathrm{SiO}_{2} / \mathrm{R} 2 \mathrm{O} 3 \mathrm{Kr}$ & $\mathrm{Al}_{2} \mathrm{O}_{3} / \mathrm{Fe}_{2} \mathrm{O}_{3}$ \\
\hline A1 & - & - & 31 & 14 & 6 & 1,4 & 3,76 & 2,95 & 3,66 \\
\hline $\mathrm{A} 2$ & - & - & 31 & 16 & 3 & 1,2 & 3,29 & 2,94 & 8,37 \\
\hline Bt1 & - & - & 43 & 26 & 4 & 1,7 & 2,81 & 2,56 & 10,2 \\
\hline $\mathrm{Bt} 2$ & - & - & 52 & 45 & 6 & 2,1 & 1,96 & 1,81 & 11,77 \\
\hline
\end{tabular}

Dados: Embrapa Agrossilvipastoril (2015). Data: Embrapa Agrossilvipastoril (2015).

\section{Perfil n ${ }^{\circ} 2$ Juina}

Classificação: ARGISSOLO VERMELHO AMARELO Distrófico nitossólico, A moderado, textura média, relevo ondulado, município de Juína-MT, floresta tropical subperenifólia.

Localização, município e estado: coordenadas $11^{\circ} 36^{\prime} 39.55^{\prime} \mathrm{S}$ e 58³6’38.80" W, município de Juína/MT, Faz. LusoBrasileira.

Situação, declive e cobertura vegetal sobre o perfil: trincheira aberta em área de mata, no terço inferior da vertente longa.

Altitude: $305 \mathrm{~m}$

Litologia e formação geológica: Cretáceo, Formação Utiariti

Material originário: sedimentos argilo-arenosos.

Pedregosidade: Ausente.

Rochosidade: Ausente.

Relevo local: ondulado.

Relevo regional: Suave -ondulado a ondulado.

Erosão: Erosão antrópica não observada. Ravina natural.

Drenagem: Bem drenado.

Vegetação primária: floresta equatorial subperenifólia com castanheiras (Bertholetia excelsa), sob ação antrópica.

Uso atual: área de exploração com castanheiras.

Descrito e coletado por: Silvio Tulio Spera e Nilton César Morel.

Data da descrição: 26/06/2014.
Observações: Coletado em trincheira escavada em barranco de ravina natural, em mata.

Descrição morfológica

A1: 0 - $7 \mathrm{~cm}$; bruno claro (7,5 YR 5/3 seco), bruno acinzentado (7,5 YR 5/2 úmido); franco arenosa; fraca, granular pequena e média q.s.d. em granular muito pequena; solta, muito friável, não plástico e não pegajoso; muitos poros muitos pequenos, pequenos, médios e comuns grandes; abundantes raízes muito finas, finas e médias; transição plana e clara.

A2: 7 - $29 \mathrm{~cm}$; bruno claro (7,5 YR 5/4 seco), bruno claro $(7,5$ YR 5/3 úmido); franco argilo arenosa; fraca, granular pequena e média q.s.d. em granular muito pequena; solta, muito friável, não plástico e não pegajoso; muitos poros muitos pequenos, pequenos, médios e comuns grandes; abundantes raízes muito finas, finas e médias; transição plana e abrupta.

Bt1: 29 - $44 \mathrm{~cm}$; bruno (7,5 YR 5/5 úmido); franco arenosa; fraca, blocos subangulares pequeno e médio q.s.d. em moderada, blocos subangulares pequeno e muito pequeno e granular pequena; macia, friável, ligeiramente plástico e ligeiramente pegajoso; cerosidade pouca e fraca, poros comuns muito pequenos e pequenos, raros médios; raízes comuns muito finas; transição plana e gradual.

Bt2: 44 - $180 \mathrm{~cm}+$; bruno (7,5 YR 5/6 úmido); franco arenosa; fraca a moderada, blocos subangulares pequeno e médio q.s.d. em granular pequeno; macia, friável a ligeiramente dura, 
ligeiramente plástico e ligeiramente pegajoso; cerosidade comum e fraca, poros comuns muito pequenos e pequenos, raros médios; raízes poucas muito finas; transição plana e gradual.

Bt3/C: $180 \mathrm{~m}+$; bruno (7,5 YR 5/7 úmido); franco argilo arenosa, coletado com trado até $270 \mathrm{~m}$; ligeiramente plástico e ligeiramente pegajoso.

Lençol freático profundo. Castanheiras de vários portes presentes.
Análises físicas e químicas

Tabela 5. Granulometria das camadas do perfil $\mathrm{n}^{\circ} 2$ do castanhal da área de Juína-MT.

Table 5. Particle size of the layers of the profile nr. 2 of sampled in a soil profile of an area of Brazil-nuts occurrence, Juína-MT.

\begin{tabular}{cccccc}
\hline \multirow{2}{*}{ Camada } & Espessura & Argila & Silte & Areia & \multirow{2}{*}{$\begin{array}{c}\text { Relação } \\
\text { Silte/Argila }\end{array}$} \\
\cline { 2 - 4 } & $\mathrm{cm}$ & $------\mathrm{g} \mathrm{kg}^{-1}$ & ------ & 0,57 \\
$\mathrm{~A} 1$ & $0-7$ & 140 & 80 & 680 & 0,61 \\
$\mathrm{~A} 2$ & $7-29$ & 160 & 98 & 642 & 0,3 \\
$\mathrm{Bt1}$ & $29-44$ & 160 & 48 & 792 & 0,33 \\
$\mathrm{Bt} 2$ & $44-180$ & 180 & 60 & 660 & 0,41 \\
$\mathrm{Bt3} / \mathrm{C}$ & $180-280$ & 180 & 74 & 646 & \\
\hline Dados: Embrapa Agrossilvipastoril (2015). Data: Embrapa Agrossilvipastoril
\end{tabular}

(2015).

Tabela 6. Resultados analíticos químicos das camadas do perfil $\mathrm{n}^{\circ} 2$ do castanhal da área de Juína-MT.

Table 6. Chemical analytical results of sampled layers of the profile nr. 2 of sampled in a soil profile of an area of Brazil-nuts occurrence, Juína-MT.

\begin{tabular}{|c|c|c|c|c|c|c|c|c|c|}
\hline \multirow{2}{*}{ Camada } & $\mathrm{pH}$ & $\mathrm{Ca}^{2+}$ & $\mathrm{Mg}^{2+}$ & $\mathrm{K}^{+}$ & $\mathrm{Al}^{3+}$ & $\mathrm{T}$ & $\mathrm{P}$ & $\mathrm{V}$ & $\mathrm{m}$ \\
\hline & água & \multicolumn{4}{|c|}{$\mathrm{cmol}_{\mathrm{c}} \mathrm{dm}^{-3}$} & \multicolumn{2}{|c|}{$\mathrm{mg} \mathrm{dm}^{-3}$} & \multicolumn{2}{|c|}{$\%$} \\
\hline A1 & - & 0,4 & - & 0,07 & 1,2 & 7,9 & 2 & 6 & 71 \\
\hline A2 & - & 0,3 & - & 0,05 & 1,2 & 7,3 & 3 & 5 & 75 \\
\hline Bt1 & - & 0,2 & - & 0,03 & 0,6 & 3,7 & 1 & 5 & 75 \\
\hline $\mathrm{Bt} 2$ & - & 0,1 & - & 0,01 & 0,6 & 3,4 & 1 & 3 & 86 \\
\hline $\mathrm{Bt} 3 / \mathrm{C}$ & - & 0,1 & - & 0,01 & 0,4 & 1,4 & $<1$ & 7 & 80 \\
\hline \multirow[t]{2}{*}{ Camada } & $\mathrm{C}_{\text {org }}$ & $\mathrm{N}_{\text {total }}$ & \multicolumn{4}{|c|}{ Ataque sulfúrico } & \multicolumn{3}{|c|}{ Relações moleculares } \\
\hline & $\mathrm{g} \mathrm{kg}^{-1}$ & & $\mathrm{SiO}_{2}$ & $\mathrm{Al}_{2} \mathrm{O}_{3}$ & $\mathrm{Fe}_{2} \mathrm{O}_{3}$ & $\mathrm{TiO}_{2}$ & $\mathrm{SiO}_{2} / \mathrm{Al} 2 \mathrm{O} 3 \mathrm{Ki}$ & $\mathrm{SiO}_{2} / \mathrm{R} 2 \mathrm{O} 3 \mathrm{Kr}$ & $\mathrm{Al}_{2} \mathrm{O}_{3} / \mathrm{Fe}_{2} \mathrm{O}_{3}$ \\
\hline A1 & - & - & 56 & 50 & 10 & 2 & 1,9 & 1,69 & 7,85 \\
\hline A2 & - & - & 68 & 65 & 14 & 2,5 & 1,78 & 1,56 & 7,29 \\
\hline Bt1 & - & - & 65 & 64 & 12 & 2,5 & 1,73 & 1,54 & 8,37 \\
\hline $\mathrm{Bt} 2$ & - & - & 72 & 77 & 14 & 2,6 & 1,59 & 1,42 & 8,64 \\
\hline $\mathrm{Bt} 3 / \mathrm{C}$ & - & - & 78 & 80 & 21 & 3,1 & 1,66 & 1,42 & 5,98 \\
\hline
\end{tabular}

Dados: Embrapa Agrossilvipastoril (2015). Data: Embrapa Agrossilvipastoril (2015).

\section{Perfil $n^{\circ} 1$ Alta Floresta}

Classificação: LATOSSOLO VERMELHO AMARELO Distrófico álico, A moderado, textura média, floresta equatorial subperenifólia, relevo plano.

Localização, município e estado: coordenadas, município de Alta Floresta/MT. Coordenadas: 0956’25” S e 56²0’15” W Situação, declive e cobertura vegetal sobre o perfil: trincheira aberta em área de mata fechada, em posição nivelada do terreno, em área experimental do CEPLAC.

Altitude: $273 \mathrm{~m}$

Litologia e formação geológica: Arqueano. Complexo Xingu. Granitos metamórficos.

Material originário: Sedimentos areno-argilosos de granitos e quartzitos do Complexo Xingu.

Pedregosidade: Ausente.

Rochosidade: Ausente.

Relevo local: Plano.

Relevo regional: Plano a suave-ondulado.

Erosão: não aparente.

Drenagem: bem drenado.

Vegetação primária: floresta equatorial subperenifólia com castanheiras (Bertholetia excelsa), sob ação antrópica.

Uso atual: exploração extrativa de castanha-do-brasil.

Descrito e coletado por: Ciro A. S. Magalhães.
Descrição morfológica

A1: 0 - $8 \mathrm{~cm}$; bruno escuro (7,5 YR 3/4 úmido); argila, granular e fracos blocos subangulares.

AB: 8 - $20 \mathrm{~cm}$; bruno (7,5 YR 4/6 úmido); argila, granular e fracos blocos subangulares.

BA: $20-60 \mathrm{~cm}$; bruno forte (7,5 YR 4/6 úmido); muito argilosa, moderada, granular e fracos blocos subangulares.

Bw1: 60 - $103 \mathrm{~cm}$; bruno-avermelhado (5 YR 4/4 úmido); muito argilosa, moderada, granular e fracos blocos subangulares.

Bw2: 103 - $150 \mathrm{~cm}$; bruno-avermelhado (5 YR 4/4 úmido); muito argilosa, moderada, granular.

Bw3: 150 - $180 \mathrm{~cm}$; bruno-avermelhado (5 YR 4/8 úmido); muito argilosa, moderada, granular.

Análises físicas e químicas

Tabela 7. Granulometria do solo das camadas do perfil do castanhal da área de Alta Floresta-MT.

Table 7. Particle size of the layers of the soil profile of an area of Brazil-nuts occurrence, Alta Floresta-MT.

\begin{tabular}{|c|c|c|c|c|c|}
\hline \multirow{2}{*}{ Camada } & Espessura & Argila & Silte & Areia & \multirow{2}{*}{$\begin{array}{c}\text { Relação } \\
\text { Silte/Argila }\end{array}$} \\
\hline & $\mathrm{cm}$ & $-\cdots$ & $\mathrm{g} \mathrm{kg}^{-1}$ & --- & \\
\hline A1 & $0-8$ & 434 & 48 & 518 & 0,11 \\
\hline $\mathrm{AB}$ & $8-20$ & 500 & 64 & 435 & 0,13 \\
\hline BA & $20-60$ & 574 & 47 & 378 & 0,08 \\
\hline Bw1 & $60-103$ & 621 & 20 & 359 & 0,03 \\
\hline Bw2 & $103-150$ & 614 & 21 & 365 & 0,03 \\
\hline Bw3 & $150-180+$ & 609 & 18 & 373 & 0,03 \\
\hline
\end{tabular}


Tabela 8. Resultados analíticos químicos das camadas amostradas em perfil do castanhal da área de Alta Floresta-MT.

Table 8. Chemical analytical results of the layers of the soil profile of an area of Brazil-nuts occurrence, Alta Floresta-MT.

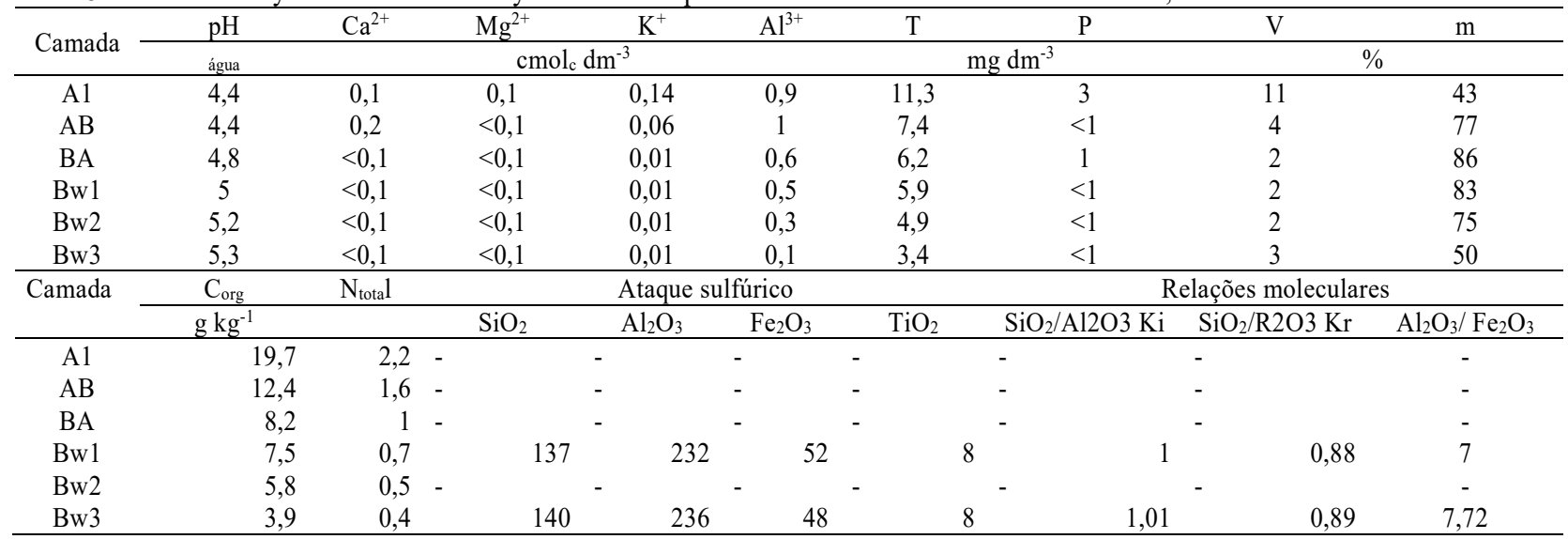

Dados: Embrapa Agrossilvipastoril (2015). Data: Embrapa Agrossilvipastoril (2015).

\section{Perfil n ${ }^{\circ} 1$ Cotriguaçu}

Classificação: LATOSSOLO VERMELHO AMARELO Distrófico álico típico, A moderado, textura muito argilosa, floresta equatorial subperenifólia, relevo plano.

Localização, município e estado: coordenadas, município de Cotriguaçu/MT. Coordenadas: 0949'16” S e 58 $17^{\prime} 22^{\prime \prime} \mathrm{W}$.

Situação, declive e cobertura vegetal sobre o perfil: trincheira aberta em área de mata fechada, em posição nivelada.

Altitude: $259 \mathrm{~m}$

Litologia e formação geológica: Arqueano. Complexo Xingu. Granitos metamórficos.

Material originário: Sedimentos areno-argilosos de granitos e quartzitos do complexo Xingu.

Pedregosidade: Ausente.

Rochosidade: Ausente.

Relevo local: Suave-ondulado.

Relevo regional: Suave-ondulado.

Erosão: não aparente.

Drenagem: acentuadamente drenado.

Vegetação primária: floresta equatorial subperenifólia com castanheiras (Bertholetia excelsa).

Uso atual: exploração extrativa de castanha-do-brasil.

Descrito e coletado por: Ciro A. S. Magalhães.

Descrição morfológica

A1: 0 - $5 \mathrm{~cm}$; bruno avermelhado; (5 YR 4/4úmido); argila, moderada granular;

AB: 5 - $19 \mathrm{~cm}$; bruno forte (7,5 YR 4/6 úmido); muito argilosa, moderada, granular e fracos blocos subangulares;

BA: 19 - $47 \mathrm{~cm}$; bruno-avermelhado (5 YR 4/4 úmido); muito argilosa, moderada, granular e fracos blocos subangulares;

Bw1: 47 - $75 \mathrm{~cm}$; bruno-avermelhado (5 YR 4/4 úmido); muito argilosa, moderada, granular e fracos blocos subangulares;

Bw2: 75 - $125 \mathrm{~cm}$; bruno-avermelhado (5 YR 4/4 úmido); muito argilosa, moderada, granular;

Bw3: 125 - $170 \mathrm{~cm}$; vermelho amarelado (5 YR 5/6 úmido); muito argilosa, moderada, granular;

Bw4: 170 - $190 \mathrm{~cm}$; vermelho amarelado (5 YR 5/6 úmido); muito argilosa, moderada, granular;
Análises físicas e químicas

Tabela 9. Granulometria do solo das camadas do perfil $\mathrm{n}^{0} 1$ do castanhal da área de Cotriguaçu-MT.

Table 9. Particle size of the layers of the profile nr. 1 of sampled in a soil profile of an area of Brazil-nuts occurrence, Cotriguaçu-MT.

\begin{tabular}{|c|c|c|c|c|c|}
\hline \multirow{2}{*}{ Camada } & Espessura & Argila & Silte & Areia & \multirow{2}{*}{$\begin{array}{c}\text { Relação } \\
\text { Silte/Argila }\end{array}$} \\
\hline & $\mathrm{cm}$ & \multicolumn{3}{|c|}{ - $\mathrm{g} \mathrm{kg}^{-1}$} & \\
\hline A1 & $0-5$ & 512 & 81 & 407 & 0,16 \\
\hline $\mathrm{AB}$ & $5-19$ & 633 & 120 & 247 & 0,19 \\
\hline BA & $19-47$ & 683 & 108 & 209 & 0,16 \\
\hline Bw1 & $47-75$ & 698 & 75 & 228 & 0,11 \\
\hline $\mathrm{Bw} 2$ & $75-125$ & 701 & 67 & 232 & 0,10 \\
\hline Bw3 & $125-170$ & 761 & 35 & 204 & 0,05 \\
\hline Bw4 & $170-190+$ & 757 & 44 & 198 & 0,06 \\
\hline
\end{tabular}

Dados: Embrapa Agrossilvipastoril (2015). Data: Embrapa Agrossilvipastoril (2015)

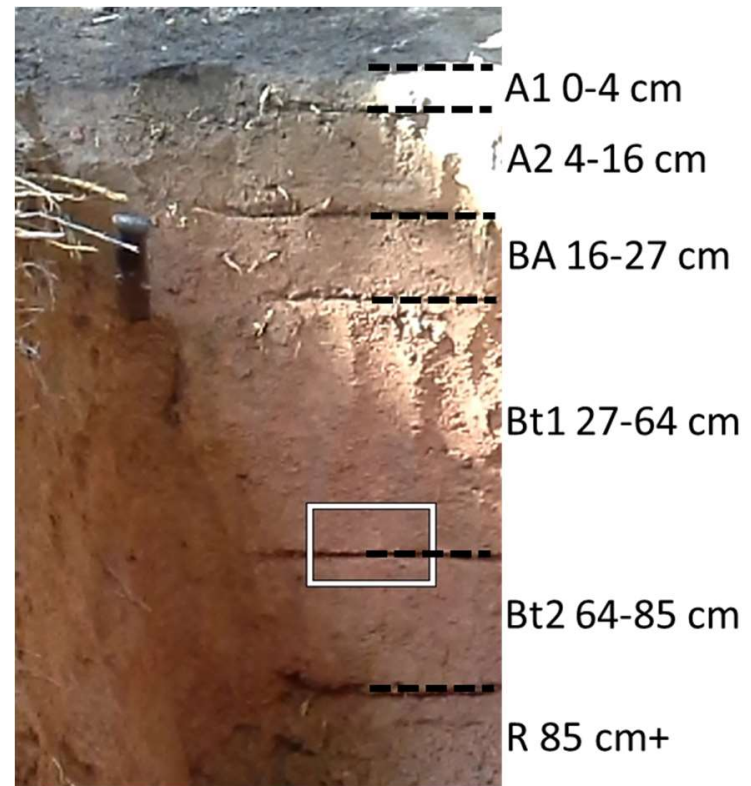

Figura 3. Perfil de Argissolo Vermelho Amarelo de Cotriguaçu-MT. O retângulo branco demarca uma camada de restrições física (menor porosidade) e química (maior saturação por alumínio) combinadas. Foto: Magalhães, C.A.S. (2014).

Figure 3. Profile of a Dystrophic Red Yellow Argisol of CotriguaçuMT. The white rectangle demarcates a layer of physical (less porosity) and chemical (higher aluminum saturation) combined constrictions. Photo: Magalhães, C.A.S. (2014). 
Tabela 10. Resultados analíticos químicos das camadas do perfil $\mathrm{n}^{\circ} 1$ do castanhal da área de Cotriguaçu-MT.

Table 10. Chemical analytical results of sampled layers of the profile nr. 1 of sampled in a soil profile of an area of Brazil-nuts occurrence, Cotriguaçu-MT.

\begin{tabular}{|c|c|c|c|c|c|c|c|c|c|}
\hline \multirow{2}{*}{ Camada } & $\mathrm{pH}$ & $\mathrm{Ca}^{2+}$ & $\mathrm{Mg}^{2+}$ & $\mathrm{K}^{+}$ & $\mathrm{Al}^{3+}$ & $\mathrm{T}$ & $\mathrm{P}$ & $\mathrm{V}$ & $\mathrm{m}$ \\
\hline & água & \multicolumn{4}{|c|}{$\mathrm{cmol}_{\mathrm{c}} \mathrm{dm}^{-3}$} & \multicolumn{2}{|c|}{$\mathrm{mg} \mathrm{dm}^{-3}$} & \multicolumn{2}{|c|}{$\%$} \\
\hline A1 & 4,4 & 0,4 & 0,1 & 0,13 & 1 & 8,2 & 3 & 7 & 62 \\
\hline $\mathrm{AB}$ & 4,3 & $<0,1$ & $<0,1$ & 0,07 & 1 & 6,7 & 1 & 4 & 77 \\
\hline $\mathrm{BA}$ & 4,6 & $<0,1$ & $<0,1$ & 0,04 & 1,1 & 6,5 & 1 & 2 & 92 \\
\hline Bw1 & 4,8 & $<0,1$ & $<0,1$ & 0,01 & 1 & 6,4 & $<1$ & 2 & 91 \\
\hline Bw2 & 4,8 & $<0,1$ & $<0,1$ & 0,01 & 1 & 6,2 & $<1$ & 2 & 91 \\
\hline Bw3 & 5 & $<0,1$ & $<0,1$ & 0,01 & 0,4 & 4,1 & $<1$ & 2 & 80 \\
\hline \multirow[t]{2}{*}{ Camada } & $\mathrm{C}_{\text {org }}$ & $\mathrm{N}_{\text {total }}$ & \multicolumn{4}{|c|}{ Ataque sulfúrico } & \multicolumn{3}{|c|}{ Relações moleculares } \\
\hline & $\mathrm{g} \mathrm{kg}^{-1}$ & & $\mathrm{SiO}_{2}$ & $\mathrm{Al}_{2} \mathrm{O}_{3}$ & $\mathrm{Fe}_{2} \mathrm{O}_{3}$ & $\mathrm{TiO}_{2}$ & $\mathrm{SiO}_{2} / \mathrm{Al} 2 \mathrm{O} 3 \mathrm{Ki}$ & $\mathrm{SiO}_{2} / \mathrm{R} 2 \mathrm{O} 3 \mathrm{Kr}$ & $\mathrm{Al}_{2} \mathrm{O}_{3} / \mathrm{Fe}_{2} \mathrm{O}_{3}$ \\
\hline A1 & 13,3 & 1,5 & - & - & - & - & - & - & - \\
\hline $\mathrm{AB}$ & 10,3 & 1,3 & - & - & - & - & - & - & - \\
\hline BA & 8,7 & 1 & - & - & - & - & - & - & - \\
\hline Bw1 & 8 & 0,8 & - & - & - & - & - & - & - \\
\hline Bw2 & 6,3 & 0,7 & 213 & 239 & 59 & 9 & 1,52 & 1,31 & 6,36 \\
\hline Bw3 & 4,2 & 0,5 & - & - & - & - & - & - & - \\
\hline Bw4 & 3,6 & 0,5 & 240 & 239 & 67 & 10 & 1,71 & 1,45 & 5,6 \\
\hline
\end{tabular}

Dados: Embrapa Agrossilvipastoril (2015). Data: Embrapa Agrossilvipastoril (2015).

\section{Perfil n ${ }^{\circ} 2$ Cotriguaçu}

Classificação: ARGISSOLO VERMELHO AMARELO Distrófico abrúptico, A moderado, álico, textura média/argilosa, floresta equatorial subperenifólia, relevo plano.

Localização, município e estado: coordenadas, município de Cotriguaçu/MT. Coordenadas 0949'11'S e 58 $16^{\prime} 03^{\prime \prime} \mathrm{W}$.

Situação, declive e cobertura vegetal sobre o perfil: trincheira aberta em área de mata fechada, em posição nivelada.

Altitude: $247 \mathrm{~m}$

Litologia e formação geológica: Arqueano. Complexo Xingu. Granitos metamórficos.

Material originário: Sedimentos areno-argilosos de granitos e quartzitos do Complexo Xingu.

Pedregosidade: Ausente.

Rochosidade: Ligeiramente rochosa.

Relevo local: Suave-ondulado.

Relevo regional: Suave-ondulado.

Erosão: não aparente.

Drenagem: moderadamente drenado.

Vegetação primária: floresta equatorial subperenifólia com castanheiras (Bertholetia excelsa).

Uso atual: exploração extrativa de castanha-do-brasil.

Descrito e coletado por: Ciro A. S. Magalhães.

$\mathrm{Na}$ profundidade de $85 \mathrm{~cm}$, foi encontrada camada de rocha cristalina, aparentemente quartzito.

Descrição morfológica

A1: 0 - $4 \mathrm{~cm}$; bruno (7,5 YR 4/3úmido); arenosa média, moderada granular;

A2: 4 - $16 \mathrm{~cm}$; bruno (7,5 YR 5/4 úmido); média arenosa, moderada, granular.

BA: 16 - $27 \mathrm{~cm}$; bruno (7,5 YR 5/4 úmido); média arenosa, moderada granular e fracos blocos subangulares.

Bt1: 27 - $64 \mathrm{~cm}$; vermelho amarelado (5 YR 5/6 úmido); argilosa, moderada e fracos blocos subangulares; cerosidade comum e fraca.
Bt2: $64-85 \mathrm{~cm}$; vermelho amarelado (5 YR 5/8 úmido); argilosa, moderada e fracos blocos subangulares; cerosidade comum e fraca.

$\mathrm{R}: 85 \mathrm{~cm}+$ : Presença de uma camada de rocha (quartzito?).

Análises físicas e químicas

Tabela 11. Granulometria das camadas do perfil $\mathrm{n}^{\circ} 2$ do castanhal da área de Cotriguaçu-MT.

Table11. Particle size of the layers of the profile nr. 2 of sampled in a soil profile of an area of Brazil-nuts occurrence, CotriguaçuMT.

\begin{tabular}{|c|c|c|c|c|c|}
\hline \multirow{2}{*}{ Camada } & Espessura & Argila & Silte & Areia & \multirow{2}{*}{$\begin{array}{c}\text { Relação } \\
\text { Silte/Argila }\end{array}$} \\
\hline & $\mathrm{cm}$ & \multicolumn{3}{|c|}{-} & \\
\hline A1 & $0-4$ & 147 & 74 & 779 & 0,50 \\
\hline A2 & $4-16$ & 229 & 79 & 691 & 0,34 \\
\hline BA & $16-27$ & 329 & 81 & 590 & 0,25 \\
\hline Bt1 & $27-64$ & 493 & 75 & 431 & 0,15 \\
\hline Bt2 & $64-85$ & 555 & 79 & 367 & 0,14 \\
\hline
\end{tabular}

Dados: Embrapa Agrossilvipastoril (2015). Data: Embrapa Agrossilvipastoril (2015).

A castanheira-do-brasil ocorre em terras firmes de mata alta, geralmente em solo argiloso ou argilo-silicoso. É uma espécie encontrada principalmente em solos pobres, bem estruturados e drenados, argilosos ou argilo-arenosos, sendo que a maior ocorrência é verificada nos solos de textura média a pesada. Não é encontrada em áreas com drenagem deficiente nem em solos excessivamente compactados, desenvolvendose bem em terras firmes e altas. Vegeta naturalmente em clima quente e úmido, conforme Muller et al. (1980).

A castanheira geralmente cresce em áreas de terra firme, e embora muitas publicações citem que a espécie prefira solos argilo-arenosos, alguns resultados preliminares de estudos do projeto Kamukaia (Embrapa) indicam que os castanhais crescem também em áreas de solos arenosos (Wadt; Souza, 2016), o que foi confirmado no presente estudo. 
Tabela 12. Resultados analíticos químicos das camadas do perfil $\mathrm{n}^{\circ} 2$ do castanhal da área de Cotriguaçu-MT.

Table 12. Chemical analytical results of sampled layers of the profile nr. 2 of sampled in a soil profile of an area of Brazil-nuts occurrence, Cotriguaçu-MT.

\begin{tabular}{|c|c|c|c|c|c|c|c|c|c|}
\hline \multirow{2}{*}{ Camada } & $\mathrm{pH}$ & $\mathrm{Ca}^{2+}$ & $\mathrm{Mg}^{2+}$ & $\mathrm{K}^{+}$ & $\mathrm{Al}^{3+}$ & $\mathrm{T}$ & $\mathrm{P}$ & $\mathrm{V}$ & $\mathrm{m}$ \\
\hline & água & \multicolumn{4}{|c|}{$\mathrm{cmol}_{\mathrm{c}} \mathrm{dm}^{-3}$} & \multicolumn{2}{|c|}{$\mathrm{mg} \mathrm{dm}^{-3}$} & \multicolumn{2}{|c|}{$\%$} \\
\hline A1 & 4,8 & 0,6 & 0,2 & 0,1 & 0,1 & 3,9 & 3 & 23 & 10 \\
\hline A2 & 4,8 & 0,3 & 0,1 & 0,08 & 0,1 & 3,2 & 1 & 19 & 14 \\
\hline BA & 4,8 & 0,2 & 0,1 & 0,08 & 0,3 & 2,9 & $<1$ & 14 & 43 \\
\hline Bt1 & 5,4 & 0,1 & $<0,1$ & 0,12 & 0,3 & 2,9 & $<1$ & 10 & 50 \\
\hline $\mathrm{Bt} 2$ & 5,4 & $<0,1$ & $<0,1$ & 0,05 & 0,2 & 2,8 & $<1$ & 7 & 50 \\
\hline \multirow[t]{2}{*}{ Camada } & $\mathrm{C}_{\text {org }}$ & $\mathrm{N}_{\text {total }}$ & \multicolumn{4}{|c|}{ Ataque sulfúrico } & \multicolumn{3}{|c|}{ Relações moleculares } \\
\hline & $\mathrm{g} \mathrm{kg}^{-1}$ & & $\mathrm{SiO}_{2}$ & $\mathrm{Al}_{2} \mathrm{O}_{3}$ & $\mathrm{Fe}_{2} \mathrm{O}_{3}$ & $\mathrm{TiO}_{2}$ & $\mathrm{SiO}_{2} / \mathrm{Al} 2 \mathrm{O} 3 \mathrm{Ki}$ & $\mathrm{SiO}_{2} / \mathrm{R} 2 \mathrm{O} 3 \mathrm{Kr}$ & $\mathrm{Al}_{2} \mathrm{O}_{3} / \mathrm{Fe}_{2} \mathrm{O}_{3}$ \\
\hline A1 & 6,3 & 0,9 & - & - & - & - & - & - & - \\
\hline A2 & 4,8 & 0,7 & - & - & - & - & - & - & - \\
\hline BA & 4 & 0,7 & - & - & - & - & - & - & - \\
\hline Bt1 & 3,1 & 0,6 & 167 & 181 & 42 & 6 & 1,57 & 1,37 & 6,77 \\
\hline Bt2 & 2,2 & 0,4 & 198 & 211 & 42 & 6 & 1,6 & 1,41 & 7,89 \\
\hline A1 & 6,3 & 0,9 & - & - & - & - & - & - & - \\
\hline A2 & 4,8 & 0,7 & - & - & - & - & - & - & - \\
\hline
\end{tabular}

Dados: Embrapa Agrossilvipastoril (2015). Data: Embrapa Agrossilvipastoril (2015).

\subsection{Caracterização mineralógica dos solos}

Os difratogramas de raios-X da amostra total e das amostras submetidas aos tratamentos, são úteis para ilustrar a análise mineralógica. Merece destaque a elevada intensidade das reflexões da caulinita em relação aos outros minerais presentes. Os resultados das análises mineralógicas das amostras mostram que estas são constituídas por caulinita, gibbsita, goethita, vermiculita com hidróxi-Al entrecamadas (VHE), anatásio e mica, que podem ser observados nos difratogramas das Figuras 4, 5, 6, 7, 8, 9, 10, 11, 12, 13, 14 e 15.Esses resultados confirmam o que foi observado por Lima et al. (2006) ao avaliarem a mineralogia de solos amazônicos em áreas de ocorrência de castanhais nativos.

A caulinita é o mineral predominante em todas as amostras, destacando-se pela expressão de suas reflexões. A observação do difratograma da amostra total permite uma comparação imediata da intensidade das reflexões de cada mineral na amostra. Na sequência observa-se que as reflexões da gibbsita são bastante expressivas também nas amostras 4 , 6, 23 e 27, e nas outras amostras, a intensidade é bastante reduzida. O mesmo se verifica para as reflexões correspondentes aos outros minerais presentes (VHE, goethita, anatásio e mica). A intensidade das reflexões reflete a proporção dos minerais na amostra. $\mathrm{Na}$ amostra número 14.1558, observou-se pequena expansão parcial na reflexão da VHE, no difratograma referente à amostra MG-saturada quando submetida à solvatação com etileno glicol, o que pode indicar também presença de esmectita, nesta amostra.

A VHE ocorre em todas as amostras, em proporções reduzidas, e sua presença é evidenciada por uma pequena reflexão que persiste aos tratamentos aplicados, deixando de ser observada apenas na amostra aquecida a $550^{\circ} \mathrm{C}$. A goethita ocorre em todas as amostras, e sua presença é evidenciada por uma pequena reflexão, observada apenas na amostra total. $\mathrm{O}$ anatásio também ocorre em quase todas as amostras, ainda que em proporções reduzidas principalmente nas amostras 13, 17 e 18. Suas reflexões são observadas apenas no difratograma da amostra aquecida a $550^{\circ} \mathrm{C}$, onde as reflexões da caulinita não são mais observadas. Sua presença está mais evidente apenas nas amostras 23 e 27 , onde estão assinaladas. A mica ocorre apenas nas amostras 23 e 27, onde é possível observar as suas reflexões diagnósticas, ainda que forma bastante reduzida.

A presença de mica foi considerada apenas nas amostras 14.1558 e 14.1560. Observa-se que os difratogramas são muito parecidos para todas as quatro amostras, variando apenas na intensidade das reflexões.

A goethita e o anatásio ocorrem em todas as amostras, em proporção bastante reduzida. A presença de goethita é observada somente no difratograma da amostra total. A mica ocorre apenas nas amostras 14.1558 e 14.1560 (Figuras 14 e 15), nas quais é possível observar as suas reflexões diagnósticas, ainda que forma bastante reduzida. Esta predominância relativa entre os minerais presentes bem como as ocorrências daqueles em proporções reduzidas podem ser observados nos difratogramas abaixo, através das reflexões diagnósticas de cada um.

Os resultados obtidos mostram coerência com os solos da região, conforme indicaram Schaeffer et al. (2008) em estudo de revisão dos solos oxídicos brasileiros. 

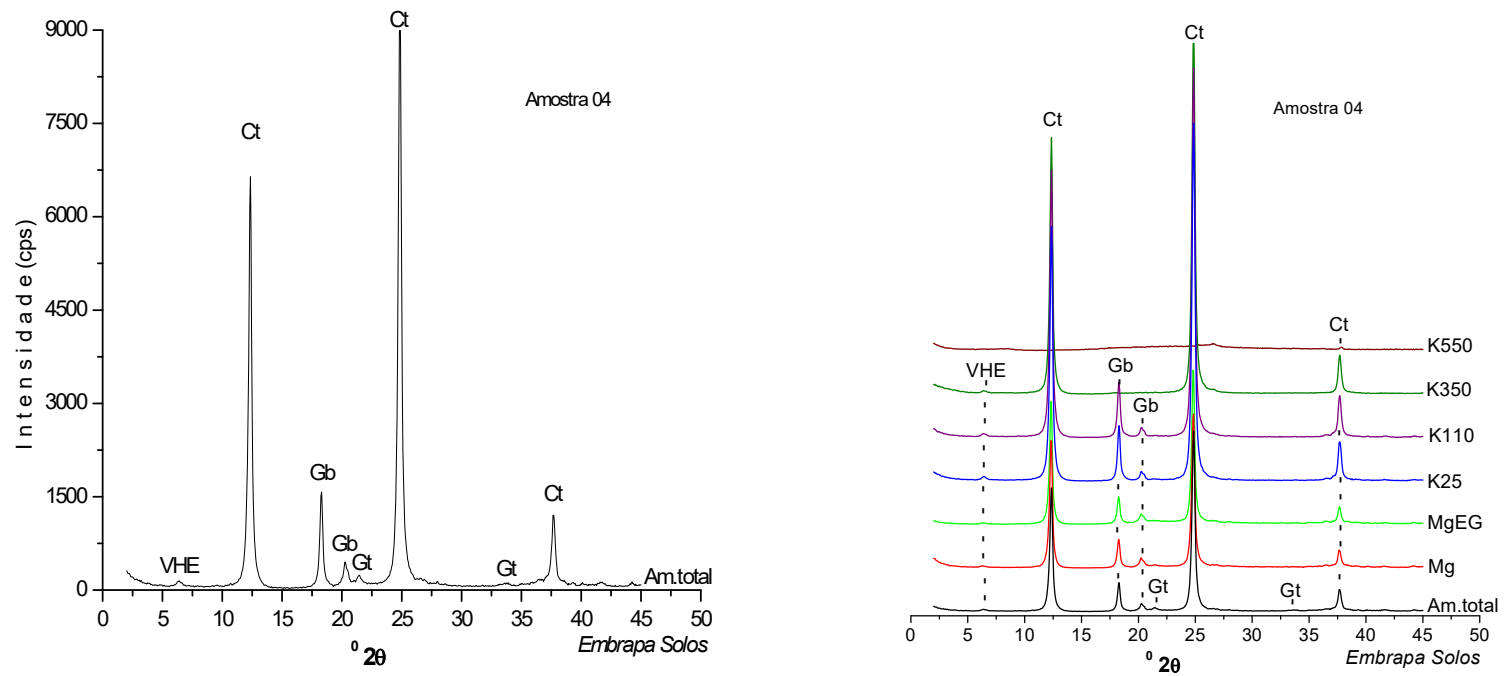

4A. Difratograma de raios-X da fração argila da amostra total.

4A. X-ray difractogram of from the clay fraction of total sample.

4B. Difratogramas de raios-X da fração argila da amostra total e amostras submetidas aos tratamentos. Montagem orientada. Radiação $\mathbf{C u} \mathbf{K a}$.

4B. X-ray difractogram of clay fraction of the total sample and samples submitted to treatment. Assembly oriented. Radiation $\mathrm{Cu}$ K- $\alpha$

VHE-vermiculita com hidróxi-Al entrecamadas; Ct-caulinita; Gb-gibbsita; Gt-goethita. Minerais predominantes: caulinita e gibbsita. Am. total - amostra não tratada, Mg e MgEG - amostra desferrificada, saturada com magnésio e, posteriormente, solvatada com Etileno Glicol, com varreduras executadas em ambas as condições. K25, K110, K350 eK550 - amostra desferrificada e saturada com potássio, com varreduras executadas à temperatura ambiente $\left(25^{\circ} \mathrm{C}\right)$ e, após aquecimento, nas temperaturas assinaladas.

Figura 4. Difratogramas de Raios-X da amostra de camada Bw1 de Latossolo Vermelho Amarelo de Alta Floresta, MT. Gráfico: Embrapa Solos, 2015.

Figure 4. X-ray difractogram of from the sample of Bw1 layer of Red Yellow Latosol of Alta Floresta, MT. Graphic: Embrapa Solos, 2015.
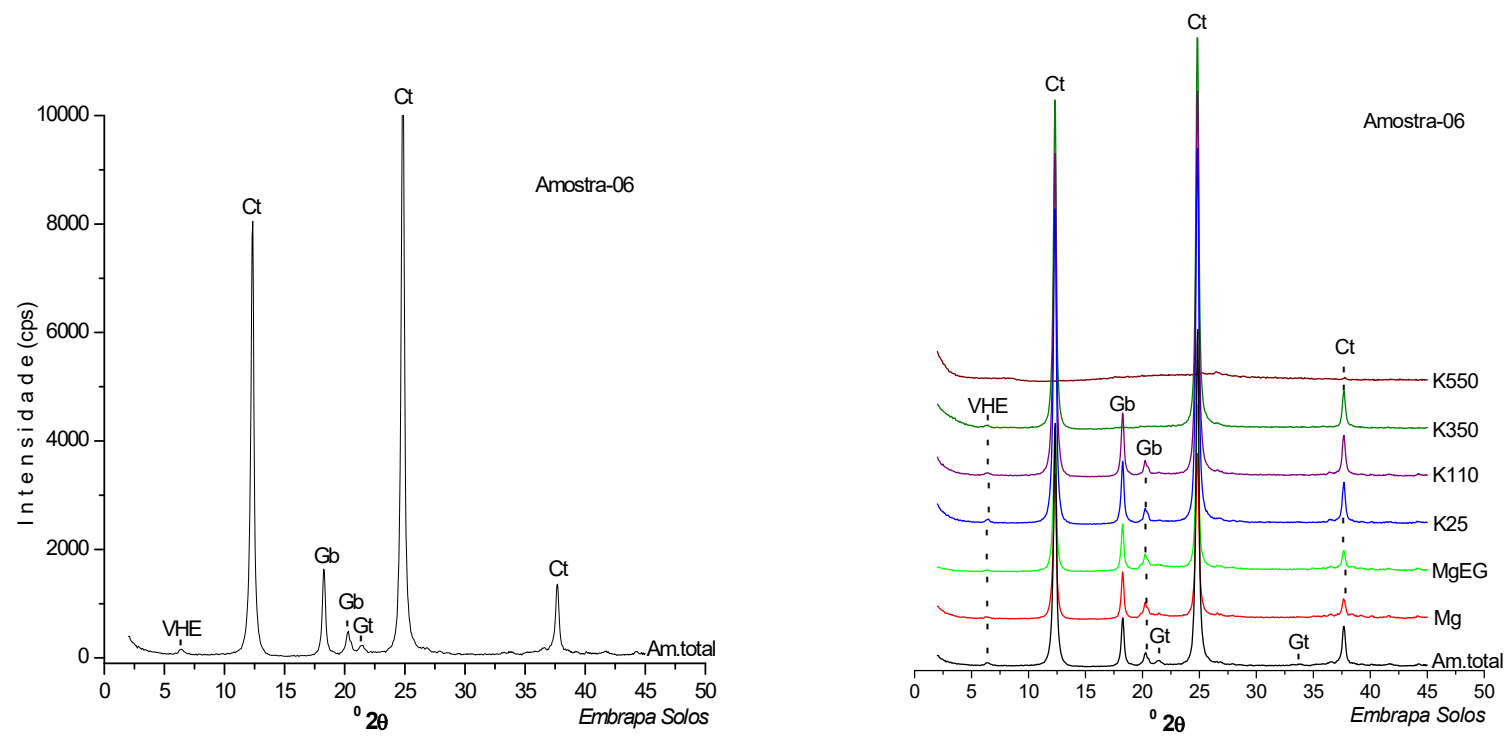

5A. Difratograma de raios-X da fração argila da amostra total. 5A. X-ray difractogram of from the clay fraction of total sample.

5B. Difratogramas de raios-X da fração argila da amostra total e amostras submetidas aos tratamentos. Montagem orientada. Radiação Cu Ka.

5B. X-ray difractogram of clay fraction of the total sample and samples submitted to treatment. Assembly oriented. Radiation $\mathrm{Cu} \mathrm{K}-\alpha$.

VHE-vermiculita com hidróxi-Al entrecamadas; Ct-caulinita; Gb-gibbsita; Gt-goethita. Minerais predominantes: caulinita e gibbsita. Am. total - amostra não tratada, Mg e MgEG - amostra desferrificada, saturada com magnésio e, posteriormente, solvatada com Etileno Glicol, com varreduras executadas em ambas as condições. K25, K110, K350 eK550 - amostra desferrificada e saturada com potássio, com varreduras executadas à temperatura ambiente $\left(25^{\circ} \mathrm{C}\right)$ e, após aquecimento, nas temperaturas assinaladas.

Figura 5. Difratogramas de Raios-X da amostra de camada Bw3 de Latossolo Vermelho Amarelo de Alta Floresta, MT. Gráfico: Embrapa Solos, 2015.

Figure 5. X-ray difractogram of from the sample of Bw3 layer of Red Yellow Latosol of Alta Floresta, MT. Graphic: Embrapa Solos, 2015. 

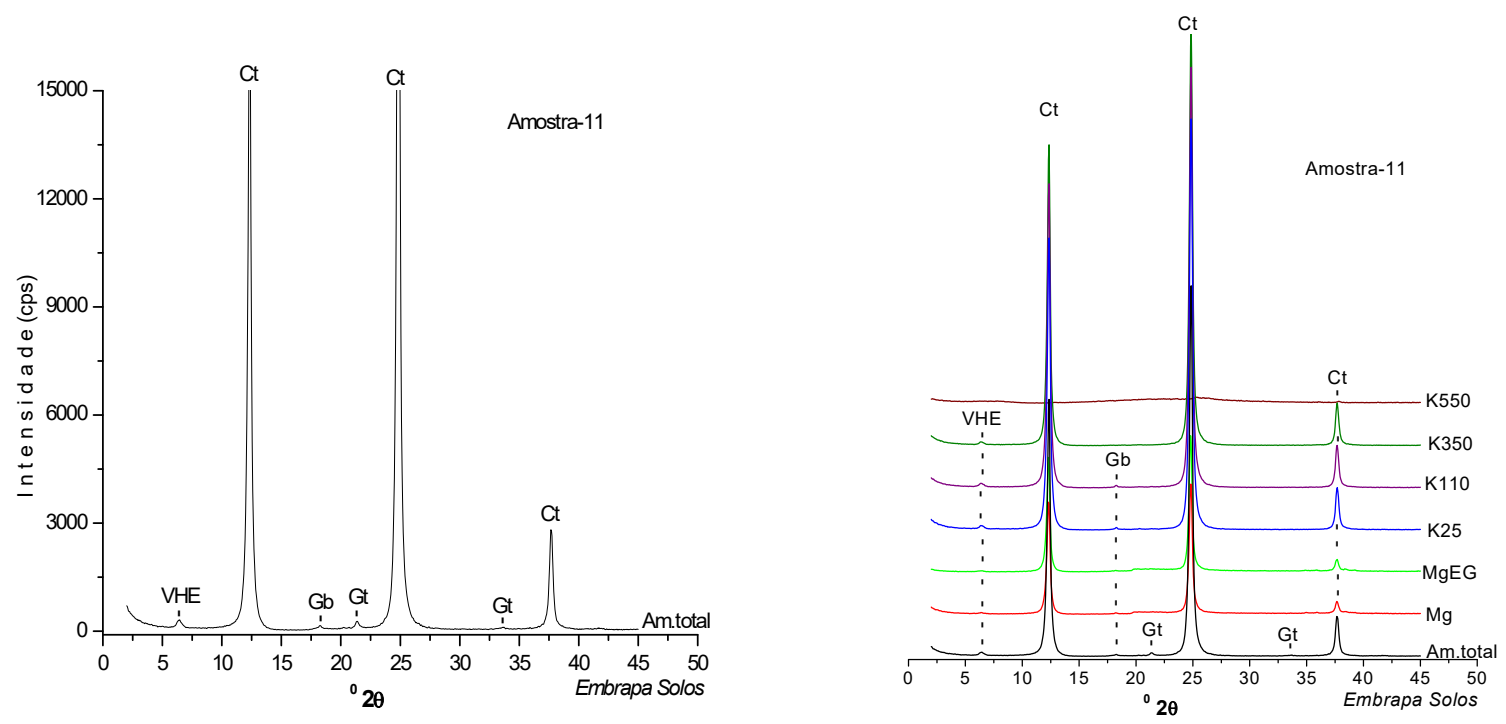

6A. Difratograma de raios-X da fração argila da amostra total.

6A. X-ray difractogram of from the clay fraction of total sample.

6B. Difratogramas de raios-X da fração argila da amostra total e amostras submetidas aos tratamentos. Montagem orientada. Radiação Cu K- $\alpha$.

6B. X-ray difractogram of clay fraction of the total sample and samples submitted to treatment. Assembly oriented. Radiation Cu K- $\alpha$.

VHE-vermiculita com hidróxi-Al entrecamadas; Ct-caulinita; Gb-gibbsita; Gt-goethita. Minerais predominantes: caulinita e gibbsita. Am. total - amostra não tratada, Mg e MgEG - amostra desferrificada, saturada com magnésio e, posteriormente, solvatada com Etileno Glicol, com varreduras executadas em ambas as condições. K25, K110, K350 eK550 - amostra desferrificada e saturada com potássio, com varreduras executadas à temperatura ambiente $\left(25^{\circ} \mathrm{C}\right)$ e, após aquecimento, nas temperaturas assinaladas.

Figura 6. Difratogramas de Raios-X da amostra de camada Bw1 de Latossolo Vermelho Amarelo de Cotriguaçu, MT. Gráfico: Embrapa Solos, 2015.

Figure 6. X-ray difractogram of from the sample of Bw1 layer of Red Yellow Latosol of Cotriguaçu, MT. Graphic: Embrapa Solos, 2015.
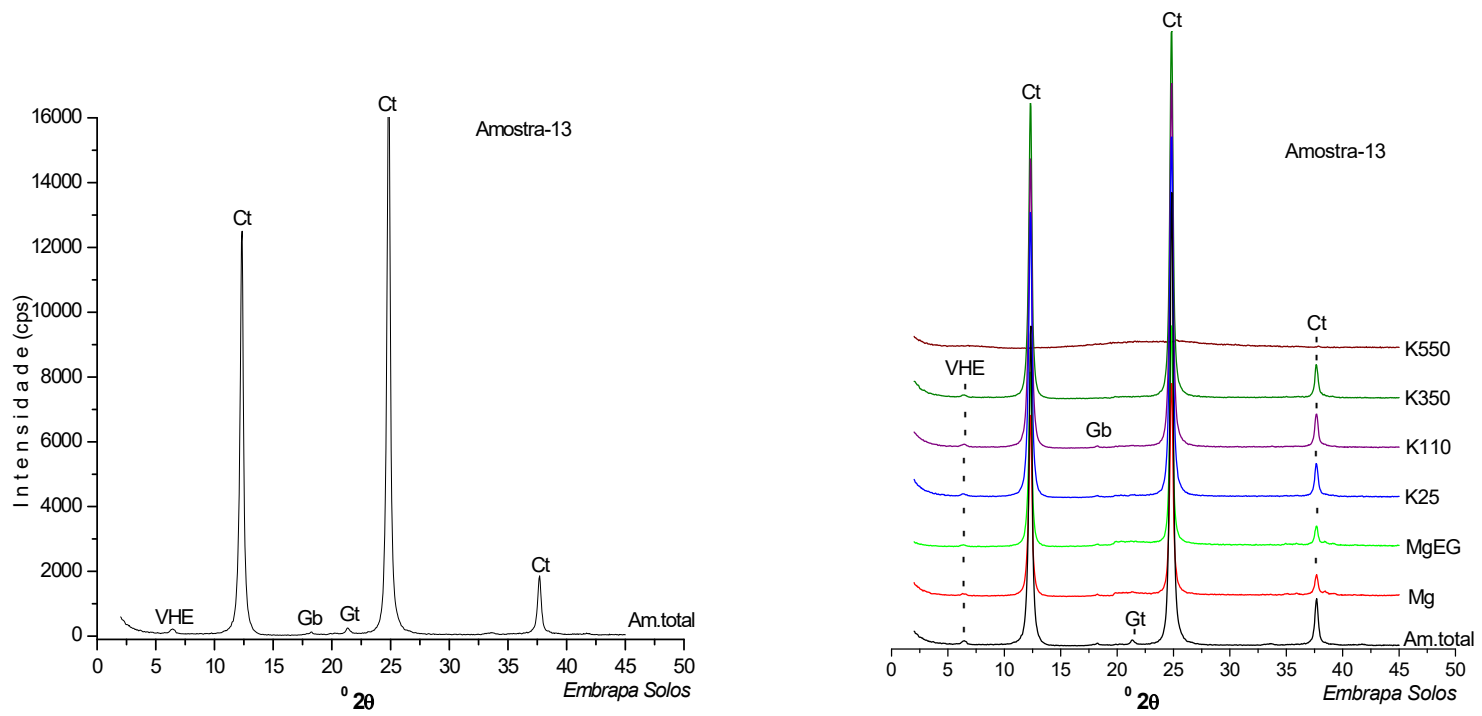

7A. Difratograma de raios-X da fração argila da amostra total.

7A. X-ray difractogram of from the clay fraction of total sample.

7B. Difratogramas de raios-X da fração argila da amostra total e amostras submetidas aos tratamentos. Montagem orientada. Radiação Cu K- $\alpha$.

7B. X-ray difractogram of clay fraction of the total sample and samples submitted to treatment. Assembly oriented. Radiation Cu K- $\alpha$.

VHE-vermiculita com hidróxi-Al entrecamadas; Ct-caulinita; Gb-gibbsita; Gt-goethita. Minerais predominantes: caulinita e gibbsita. Am. total - amostra não tratada, Mg e MgEG - amostra desferrificada, saturada com magnésio e, posteriormente, solvatada com Etileno Glicol, com varreduras executadas em ambas as condições. K25, K110, K350 eK550 - amostra desferrificada e saturada com potássio, com varreduras executadas à temperatura ambiente $\left(25^{\circ} \mathrm{C}\right)$ e, após aquecimento, nas temperaturas assinaladas.

Figura 7. Difratogramas de Raios-X da amostra de camada Bw3 de Latossolo Vermelho Amarelo de Cotriguaçu, MT. Gráfico: Embrapa Solos, 2015.

Figure 7. X-ray difractogram of from the sample of Bw3 layer of Red Yellow Latosol of Cotriguaçu, MT. Graphic: Embrapa Solos, 2015. 

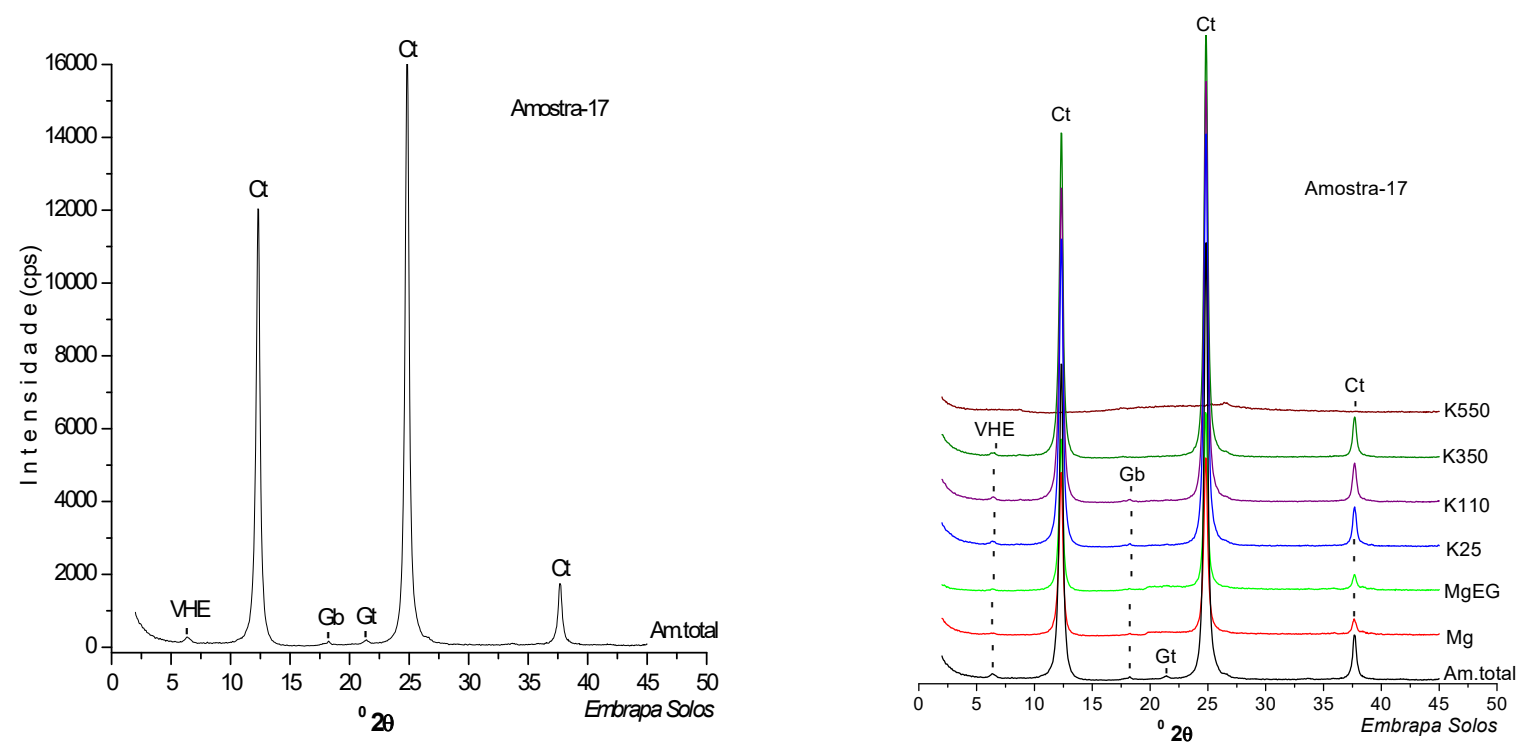

8A. Difratograma de raios- $X$ da fração argila da amostra total.

8A. X-ray difractogram of from the clay fraction of total sample.

8B. Difratogramas de raios- $\mathrm{X}$ da fração argila da amostra total e amostras submetidas aos tratamentos. Montagem orientada. Radiação Cu K- $\alpha$.

8B. X-ray difractogram of clay fraction of the total sample and samples submitted to treatment. Assembly oriented. Radiation $\mathrm{Cu} \mathrm{K}-\alpha$.

VHE-vermiculita com hidróxi-Al entrecamadas; Ct-caulinita; Gb-gibbsita; Gt-goethita. Minerais predominantes: caulinita e gibbsita. Am. total - amostra não tratada, Mg e MgEG - amostra desferrificada, saturada com magnésio e, posteriormente, solvatada com Etileno Glicol, com varreduras executadas em ambas as condições. K25, K110, K350 eK550 - amostra desferrificada e saturada com potássio, com varreduras executadas à temperatura ambiente $\left(25^{\circ} \mathrm{C}\right)$ e, após aquecimento, nas temperaturas assinaladas.

Figura 8. Difratogramas de Raios-X da amostra de camada Bt1 de Argissolo Vermelho Amarelo de Cotriguaçu, MT. Gráfico: Embrapa Solos, 2015.

Figure 8. X-ray difractogram of from the sample of Bt1 layer of Red Yellow Argisol of Cotriguaçu, MT. Graphic: Embrapa Solos, 2015.
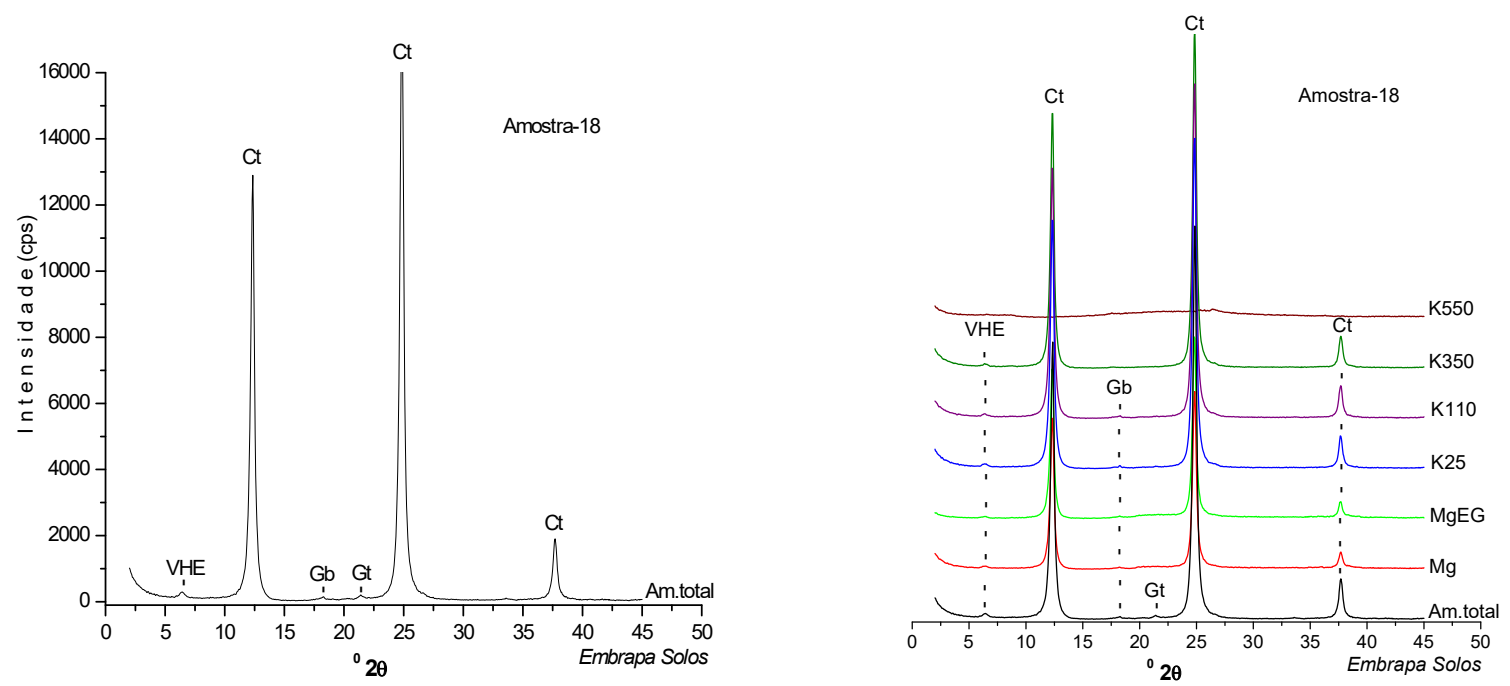

9A. Difratograma de raios-X da fração argila da amostra total.

9A. X-ray difractogram of from the clay fraction of total sample.

9B. Difratogramas de raios-X da fração argila da amostra total e amostras submetidas aos tratamentos. Montagem orientada. Radiação Cu K- $\alpha$.

9B. X-ray difractogram of clay fraction of the total sample and samples submitted to treatment. Assembly oriented. Radiation Cu K- $\alpha$.

VHE-vermiculita com hidróxi-Al entrecamadas; Ct-caulinita; Gb-gibbsita; Gt-goethita. Minerais predominantes: caulinita e gibbsita. Am. total - amostra não tratada, Mg e MgEG - amostra desferrificada, saturada com magnésio e, posteriormente, solvatada com Etileno Glicol, com varreduras executadas em ambas as condições. $\mathbf{K 2 5}$, K110, K350 eK550 - amostra desferrificada e saturada com potássio, com varreduras executadas à temperatura ambiente $\left(25^{\circ} \mathrm{C}\right)$ e, após aquecimento, nas temperaturas assinaladas.

Figura 9. Difratogramas de Raios-X da amostra de camada Bt2 de Argissolo Vermelho Amarelo de Cotriguaçu, MT. Gráfico: Embrapa Solos, 2015.

Figure 9. X-ray difractogram of from the sample of Bt2 layer of Red Yellow Argisol of Cotriguaçu, MT. Graphic: Embrapa Solos, 2015. 

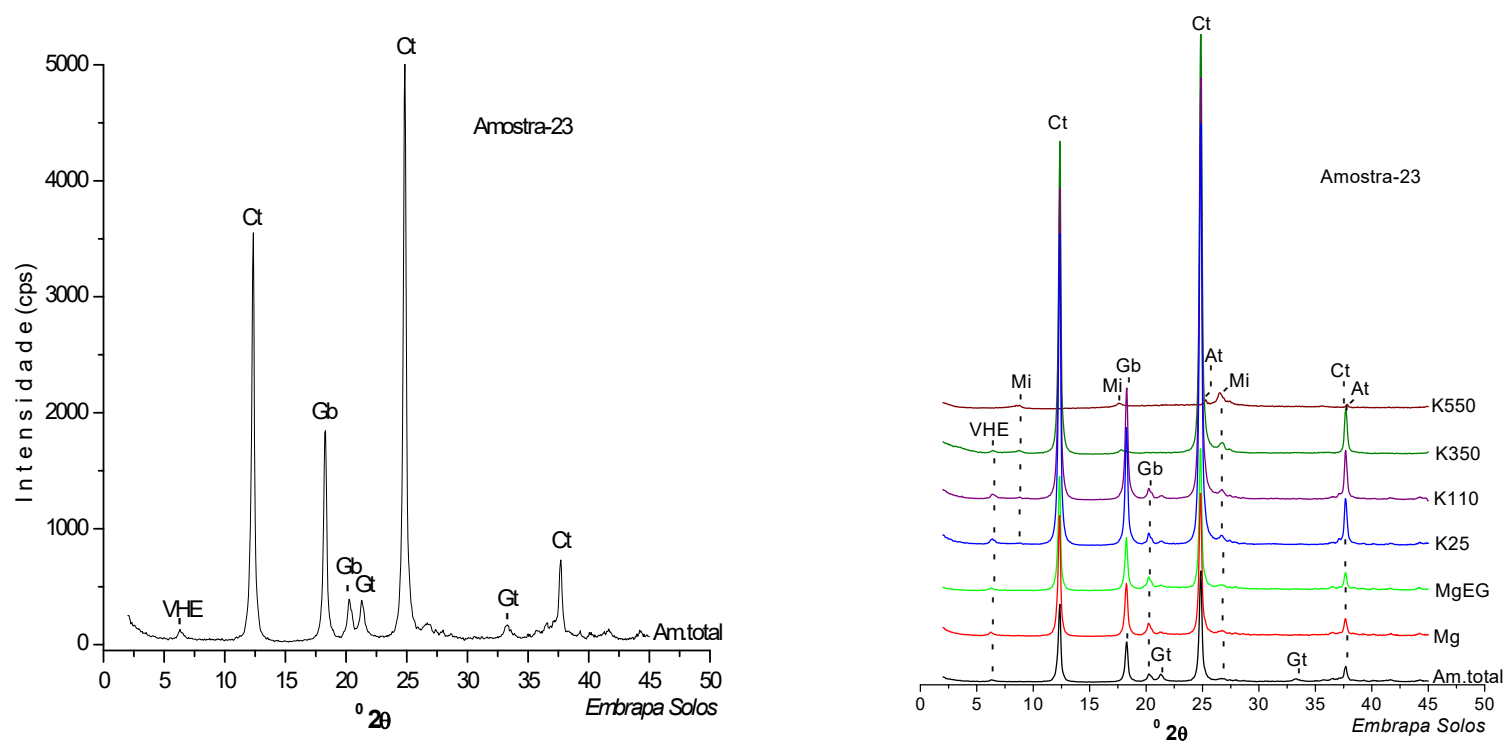

10A. Difratograma de raios-X da fração argila da amostra total.

10A. X-ray difractogram of from the clay fraction of total sample.

10B. Difratogramas de raios-X da fração argila da amostra total e amostras submetidas aos tratamentos. Montagem orientada. Radiação Cu K- $\alpha$.

10B. X-ray difractogram of clay fraction of the total sample and samples submitted to treatment. Assembly oriented. Radiation $\mathrm{Cu} \mathrm{K}-\alpha$.

VHE-vermiculita com hidróxi-Al entrecamadas; Ct-caulinita; Gb-gibbsita; Gt-goethita. Minerais predominantes: caulinita e gibbsita. Am. total - amostra não tratada, Mg e MgEG - amostra desferrificada, saturada com magnésio e, posteriormente, solvatada com Etileno Glicol, com varreduras executadas em ambas as condições. K25, K110, K350 eK550 - amostra desferrificada e saturada com potássio, com varreduras executadas à temperatura ambiente (25 $\left.{ }^{\circ} \mathrm{C}\right)$ e, após aquecimento, nas temperaturas assinaladas.

Figura 10. Difratogramas de Raios-X da amostra de camada Bw1 de Latossolo Vermelho Amarelo de Itaúba, MT. Gráfico: Embrapa Solos, 2015.

Figure 10. X-ray difractogram of from the sample of Bw1 layer of Red Yellow Latosol of Itaúba, MT. Graphic: Embrapa Solos, 2015.

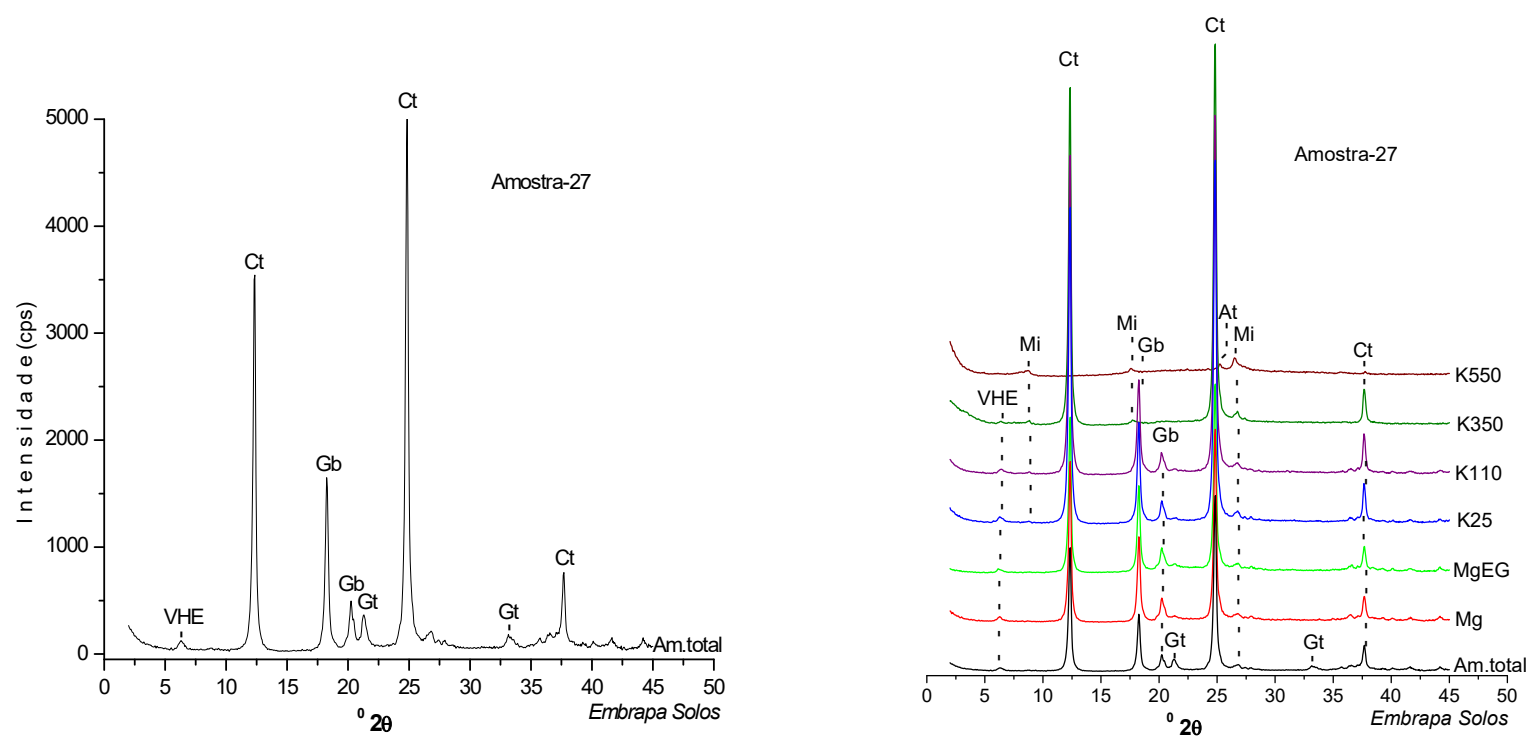

11A. Difratograma de raios-X da fração argila da amostra total.

11A. X-ray difractogram of from the clay fraction of total sample.

11B. Difratogramas de raios-X da fração argila da amostra total e amostras submetidas aos tratamentos. Montagem orientada. Radiação Cu K- $\alpha$.

11B. X-ray difractogram of clay fraction of the total sample and samples submitted to treatment. Assembly oriented. Radiation $\mathrm{Cu} \mathrm{K}-\alpha$.

VHE-vermiculita com hidróxi-Al entrecamadas; Ct-caulinita; Gb-gibbsita; Gt-goethita. Minerais predominantes: caulinita e gibbsita. Am. total - amostra não tratada, Mg e MgEG - amostra desferrificada, saturada com magnésio e, posteriormente, solvatada com Etileno Glicol, com varreduras executadas em ambas as condições. K25, K110, K350 eK550 - amostra desferrificada e saturada com potássio, com varreduras executadas à temperatura ambiente $\left(25^{\circ} \mathrm{C}\right)$ e, após aquecimento, nas temperaturas assinaladas.

Figura 11. Difratogramas de Raios-X da amostra de camada Bw5 de Latossolo Vermelho Amarelo de Itaúba, MT. Gráfico: Embrapa Solos, 2015.

Figure 11. X-ray difractogram of from the sample of Bw5 layer of Red Yellow Latosol of Itaúba, MT. Graphic: Embrapa Solos, 2015. 

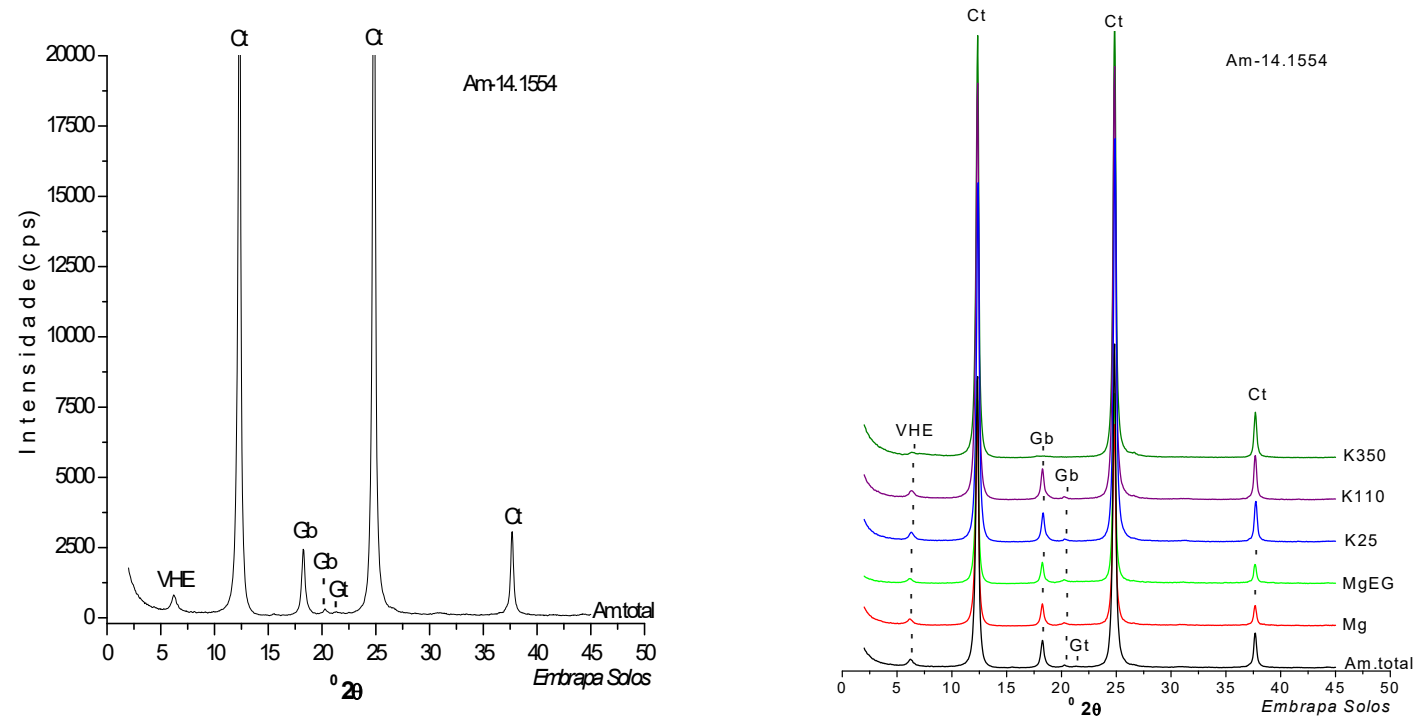

12A. Difratograma de raios-X da fração argila da amostra total. 12A. X-ray difractogram of from the clay fraction of total sample.

12B. Difratogramas de raios-X da fração argila da amostra total e amostras submetidas aos tratamentos. Montagem orientada. Radiação $\mathrm{Cu} \mathrm{K}-\alpha$

12B. X-ray difractogram of clay fraction of the total sample and samples submitted to treatment. Assembly oriented. Radiation $\mathrm{Cu} \mathrm{K}-\alpha$.

VHE-vermiculita com hidróxi-Al entrecamadas; Ct-caulinita; Gb-gibbsita; Gt-goethita. Minerais predominantes: caulinita e gibbsita. Am. total - amostra não tratada, Mg e MgEG - amostra desferrificada, saturada com magnésio e, posteriormente, solvatada com Etileno Glicol, com varreduras executadas em ambas as condições. $\mathbf{K 2 5}, \mathbf{K 1 1 0 , ~} \mathbf{K 3 5 0} \mathbf{e K 5 5 0}$ - amostra desferrificada e saturada com potássio, com varreduras executadas à temperatura ambiente $\left(25^{\circ} \mathrm{C}\right)$ e, após aquecimento, nas temperaturas assinaladas.

Figura 12. Difratogramas de Raios-X da amostra de camada Bt1 de perfil n ${ }^{\circ} 1$ de Argissolo Vermelho Amarelo, de Juína, MT. Gráfico: Embrapa Solos, 2015 .

Figure 12. X-ray difractogram of from the sample of Bt1 layer of the profile nr. 1 of a Red Yellow Argisol of Juína, MT. Graphic: Embrapa Solos, 2015
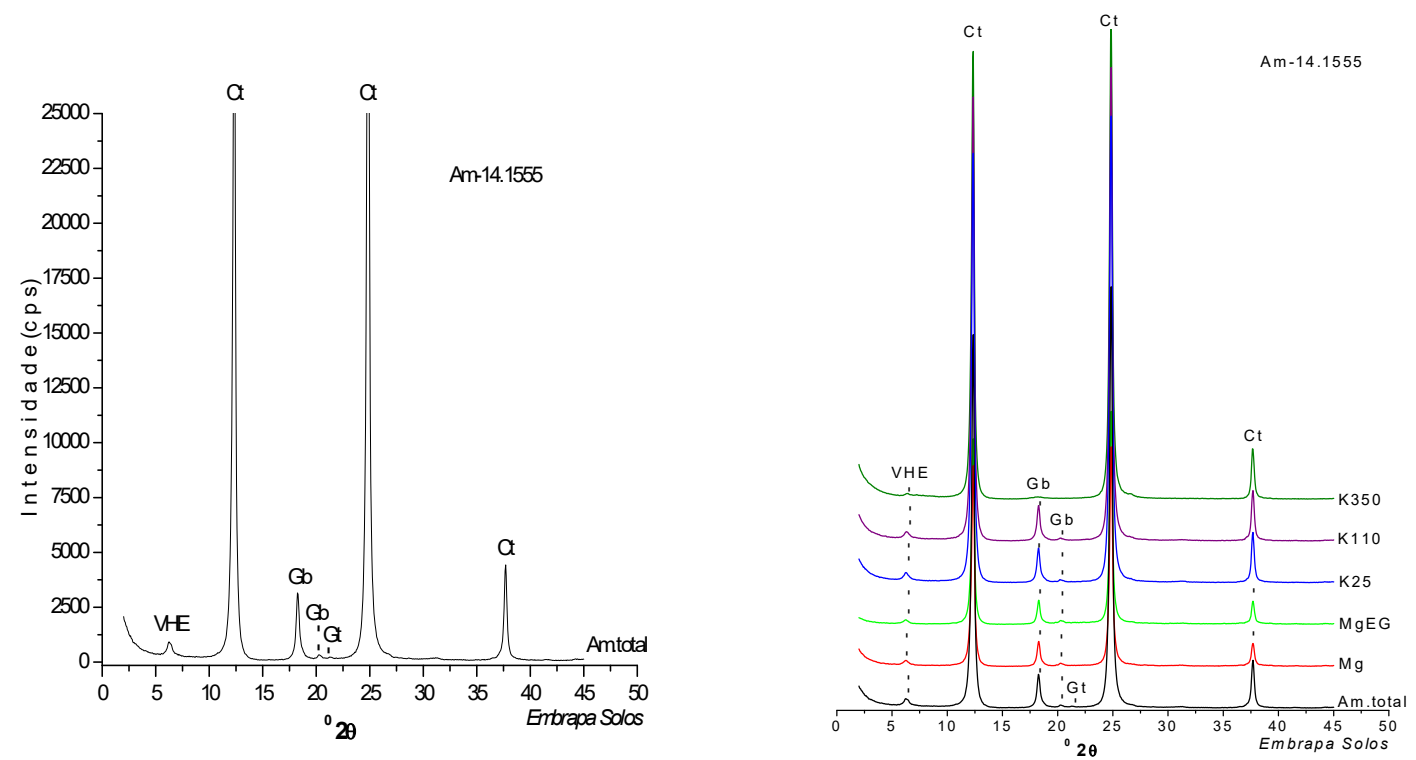

13A. Difratograma de raios-X da fração argila da amostra total. 13A. X-ray difractogram of from the clay fraction of total sample.

13B. Difratogramas de raios-X da fração argila da amostra total e amostras submetidas aos tratamentos. Montagem orientada. Radiação Cu K- $\alpha$.

13B. X-ray difractogram of clay fraction of the total sample and samples submitted to treatment. Assembly oriented. Radiation $\mathrm{Cu} \mathrm{K}-\alpha$.

VHE-vermiculita com hidróxi-Al entrecamadas; Ct-caulinita; Gb-gibbsita; Gt-goethita. Minerais predominantes: caulinita e gibbsita. Am. total - amostra não tratada, Mg e MgEG - amostra desferrificada, saturada com magnésio e, posteriormente, solvatada com Etileno Glicol, com varreduras executadas em ambas as condições. K25, K110, K350 eK550 - amostra desferrificada e saturada com potássio, com varreduras executadas à temperatura ambiente $\left(25^{\circ} \mathrm{C}\right)$ e, após aquecimento, nas temperaturas assinaladas.

Figura 13. Difratogramas de Raios-X da amostra de camada Bt2 de perfil n 1 de Argissolo Vermelho Amarelo, de Juína, MT. Gráfico: Embrapa Solos, 2015.

Figure 13. X-ray difractogram of from the sample of Bt2 layer of the profile nr. 1 of a Red Yellow Argisol of Juína, MT. Graphic: Embrapa Solos, 2015. 

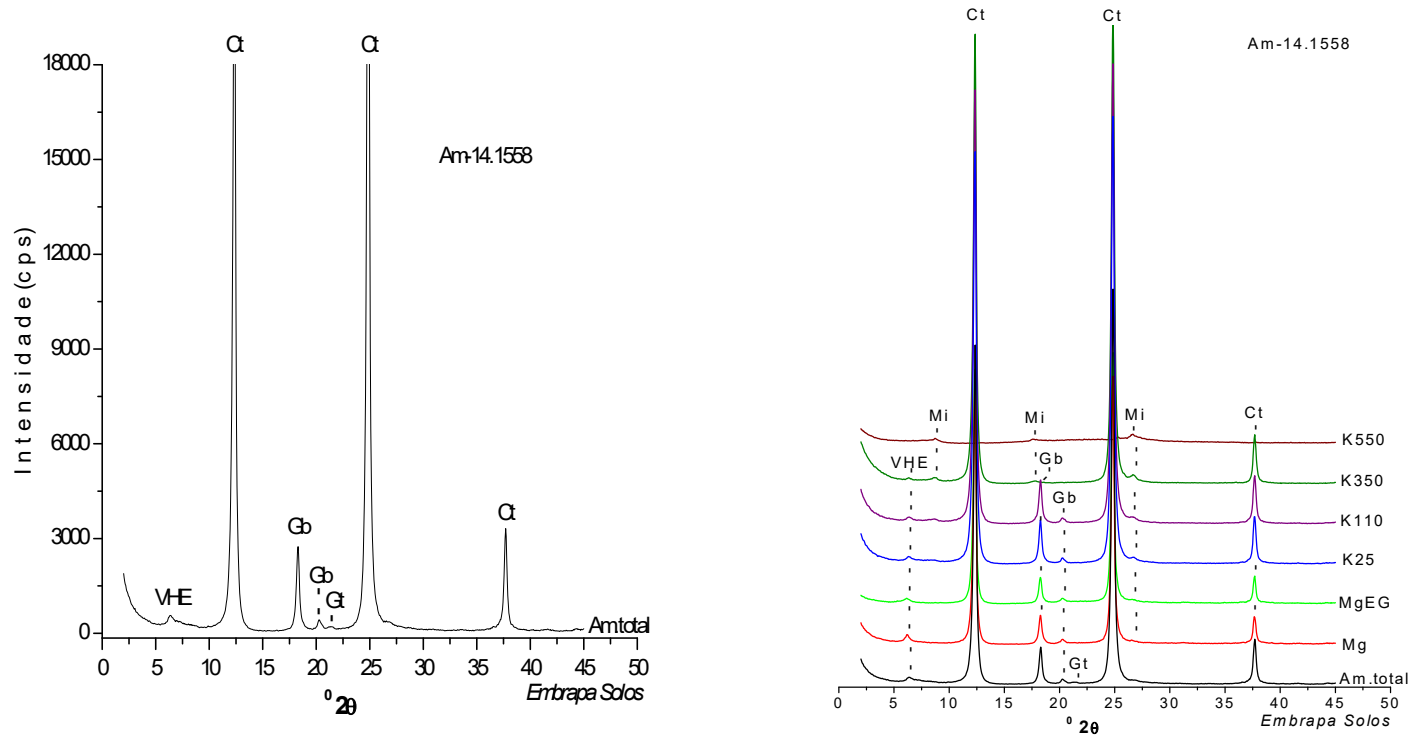

14A. Difratograma de raios-X da fração argila da amostra total. 14A. X-ray difractogram of from the clay fraction of total sample.

14B. Difratogramas de raios-X da fração argila da amostra total e amostras submetidas aos tratamentos. Montagem orientada. Radiação Cu K- $\alpha$. 14B. X-ray difractogram of clay fraction of the total sample and samples submitted to treatment. Assembly oriented. Radiation Cu K- $\alpha$.

VHE-vermiculita com hidróxi-Al entrecamadas; Ct-caulinita; Gb-gibbsita; Gt-goethita. Minerais predominantes: caulinita e gibbsita. Am. total - amostra não tratada, Mg e MgEG - amostra desferrificada, saturada com magnésio e, posteriormente, solvatada com Etileno Glicol, com varreduras executadas em ambas as condições. K25, K110, K350 eK550 - amostra desferrificada e saturada com potássio, com varreduras executadas à temperatura ambiente $\left(25^{\circ} \mathrm{C}\right)$ e, após aquecimento, nas temperaturas assinaladas.

Figura 14. Difratogramas de Raios-X da amostra de camada Bt1 de perfil no 2 de Argissolo Vermelho Amarelo de Juína, MT. Gráfico: Embrapa Solos, 2015.

Figure 14. X-ray difractogram of from the sample of Bt1 layer of the profile nr. 2 of a Red Yellow Argisol of Juína, MT. Graphic: Embrapa Solos, 2015.
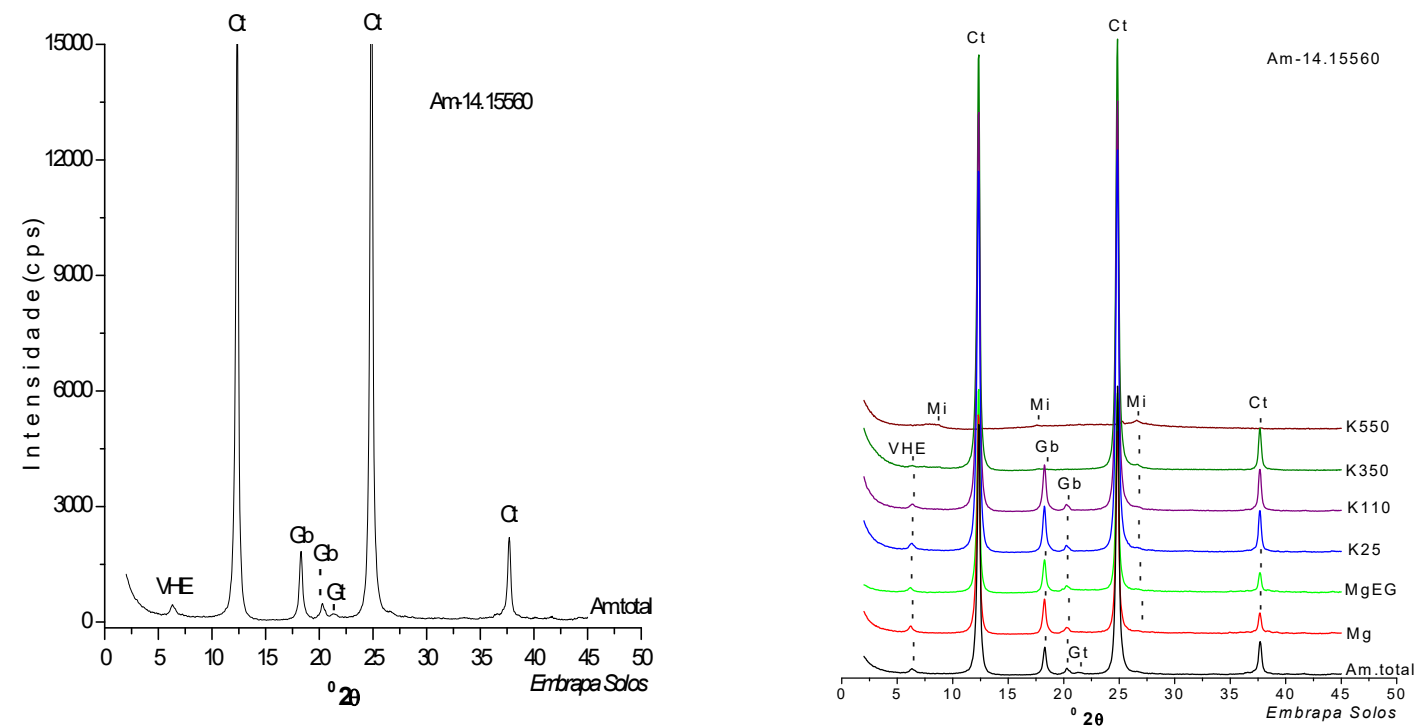

15A. Difratograma de raios-X da fração argila da amostra total.15A. X-ray difractogram of from the clay fraction of total sample.

15B. Difratogramas de raios-X da fração argila da amostra total e amostras submetidas aos tratamentos. Montagem orientada. Radiação Cu K- $\alpha$.

15B. X-ray difractogram of clay fraction of the total sample and samples submitted to treatment. Assembly oriented. Radiation Cu K- $\alpha$.

VHE-vermiculita com hidróxi-Al entrecamadas; Ct-caulinita; Gb-gibbsita; Gt-goethita. Minerais predominantes: caulinita e gibbsita. Am. total - amostra não tratada, Mg e MgEG - amostra desferrificada, saturada com magnésio e, posteriormente, solvatada com Etileno Glicol, com varreduras executadas em ambas as condições. K25, K110, K350 eK550 - amostra desferrificada e saturada com potássio, com varreduras executadas à temperatura ambiente (25 $\left.{ }^{\circ} \mathrm{C}\right)$ e, após aquecimento, nas temperaturas assinaladas.

Figura 15. Difratogramas de Raios-X da amostra de camada Bt3 de perfil nº 2 de Argissolo Vermelho Amarelo de Juína, MT. Gráfico: Embrapa Solos, 2015.

Figure 15. X-ray difractogram of from the sample of Bt3 layer of the profile nr. 2 of a Red Yellow Argisol of Juína, MT. Graphic: Embrapa Solos, 2015 
Os resultados da mineralogia do solo indicam que a castanheira-do-brasil ocorre em solos silicosos, conforme já afirmara Muller et al. (1980). No presente estudo, os Latossolos e Argissolos identificados têm predomínio de argila caulinita, o que confere aos mesmos, um caráter silicoso. Solos da floresta amazônica normalmente se diferenciam de solos de Cerrados pelo predomínio da argila caulinita, uma vez que os solos de Cerrados são predominantemente oxídicos (óxidos de Fe e Al), conforme descrevem Álvarez et al. (1996).

A preferência ou ocorrência da castanheira-do-brasil por solos não oxídicos, comuns no Cerrado pode permitir inferir que a espécie não encontra no ambiente de Cerrados condições adequadas de solo e/ou clima que favoreça o desenvolvimento dos castanhais. Isso tem importância na definição de áreas de cultivo não nativo de castanhais comerciais. Clement (1994) indica o cultivo da espécie somente naquelas áreas em que ocorre naturalmente.

\section{CONCLUSÕES}

Os solos descritos sob as áreas de ocorrência de castanheira-do-brasil no estado de Mato Grosso são ácidos, de textura variando de arenosa a muito argilosa, de baixa fertilidade natural e, às vezes, com elevado teor de alumínio, entretanto, são solos cauliníticos ou cauliníticos-gibbsíticos, o que os diferenciam da maioria dos solos de cerrados;

São solos dos grandes grupos Argissolos Vermelho Amarelos distróficos e Latossolos Vermelho Amarelos distróficos de relevo plano a ondulado predominam entre os solos nas áreas de ocorrência de castanheira-do-brasil no norte de Mato Grosso;

A presença de elevada saturação por alumínio tóxico em amostras da superfície de solos sob as áreas de ocorrência de castanheira-do-brasil, indicam que o crescimento e desenvolvimento da espécie não são afetados por este atributo químicos do solo;

A castanheira-do-brasil não foi observada em condição de solo com lençol freático pouco profundo, ainda que tenha sido constatada ocorrência da espécie em uma área com solo pouco profundo não encharcado;

Os valores $\mathrm{Ki}$ dos horizontes diagnósticos dos solos estudados foram inferiores a 2,2 indicando serem solos bem intemperizados.

\section{REFERÊNCIAS}

ALVAREZ V., V. H.; FONTES, L. E. F.; FONTES, M. P. F. (Ed.). O solo nos grandes domínios morfoclimáticos do Brasil e o desenvolvimento sustentável. Viçosa: UFVDPS, $1996.930 \mathrm{p}$.

BRANCO, P. M. Dicionário de Mineralogia. 3. ed. Porto Alegre: Sagra, 1987. 362 p.

CALDERANO, S. B.; DUARTE, M. N.; GREGORIS, G. Análise mineralógica das frações finas do solo por difratometria de raios-X: revisão e atualização da metodologia e critérios usados na Embrapa Solos. Rio de Janeiro: Embrapa Solos, 2009. (Comunicado Técnico, 53).

CLEMENT, C. R. Brazil nut. In: CLAY, J. W.; CLEMENT, C. R. (Org.). Selected species and strategies to enhance income generation from Amazonian forests. FAO: Roma. 1993. p.115-127.

COSTA, M. G.; TONINI, H.; MENDES FILHO, P. Atributos do solo relacionados com a produção da castanheira-dobrasil (Bertholletia excelsa). Floresta e Ambiente,
Seropédica, v. 24, n. 10, p. e20150042, 2017. DOI: https://dx.doi.org/10.1590/2179-8087.004215

DONAGEMMA, G. K.; CAMPOS, D. V. B.; CALDERANO, S. B.; TEIXEIRA, W.G.; VIANA, J.H.M. Manual de métodos de análise de solos. Rio de Janeiro: Embrapa Solos, 2011. 230 p. (Documentos, 132).

EMBRAPA_EMPRESA BRASILEIRA DE PESQUISA AGROPECUÁRIA. Sistema Brasileiro de Classificação de Solos. 3.ed. rev. e aum. Brasília: EMBRAPA, 2013, 353 p.

ICDD_INTERNATIONAL CENTRE FOR DIFFRACTION DĀTA. ICDD Product Brochures and Flyers. 2016. Disponível em: <http://www.icdd.com/products/pdf4minerals.htm>. Acesso em: 07 de outubro de 2016.

KLUCZKOVSKI, A. M.; MARTINS, M.; MUNDIM, S. M.; SIMÕES, R. H.; NASCIMENTO, K. S.; MARINHO, H. A.; KLUCZKOVSKI JUNIOR, A. Properties of Brazil nuts: a review. African Journal of Biotechnology, Nairobi, v. 14, n. 8, p. 642-648, 2015. DOI: https://dx.doi.org/10.5897/AJB2014.14184

LIMA, H. N.; MELLO, J. W. V.; SCHAEFER, C. E. G. R.; KER, J. C.; LIMA, A. M. N. Mineralogia e química de três solos de uma toposseqüência da bacia sedimentar do Alto Solimões, Amazônia ocidental. Revista Brasileira de Ciência do Solo, Viçosa, v. 30, n. 1, p. 59-68, 2006. DOI: http://dx.doi.org/10.1590/S0100-06832006000100007

MEHRA, O. P.; JACKSON, M. L. Iron oxide removal from soils and clays by a dithionite-citrate system buffered with sodium bicarbonate. In: NATIONAL CONFERENCE ON CLAYS AND CLAY MINERALS, 7. Anais... New York: Pergamon Press, 1960. p.317-327.

MULlER, C. H.; RODRIGUES, I. A.; MUlleR, A. A.; MULLER, N. R. M. Castanha-do-brasil: resultados de pesquisa. Belém: Embrapa/CPATU, 1980. 25 p. (Miscelânia, 2).

MUNSELL, A. H. MUNSELL soil color charts. New York: New Windsor, 1994. 29 p.

SALOMÃO, R. P.; ROSA, N. A.; CASTILHO, A.; MORAIS, K. A. C. Castanheira-do-Brasil recuperando áreas degradadas e provendo alimento e renda para comunidades de Amazônia Setentrional. Boletim do Museu Paraense Emílio Goeldi Ciências Naturais, Belém, v. 1, n. 2, p. 65 78. 2006.

SANTOS, R. D.; LEMOS, R. C.; SANTOS, H. G.; KER, J. C; ANJOS, L. H. C.; SHIMIZU, S. H. Manual de descrição e coleta de solo no campo. 6. ed. rev. e aum. Viçosa, Sociedade Brasileira de Ciência do Solo/SNLCS, 2013. $100 \mathrm{p}$.

SCHAEFER, C. E. G. R.; FABRIS, J. D.; KER, J. C. Minerals in the clay fraction of Brazilian Latosols (Oxisols): A review. Clay Minerals, McLean, v. 43, n. 1, p. 137-154, 2008 .

DOI: http://dx.doi.org/10.1180/claymin.2008.043.1.11

SCOLES, R.; GRIBEL, R; KLEIN, G.N. Crescimento e sobrevivência de castanheira (Bertholletia excelsa Bonpl.) em diferentes condições ambientais na região do rio Trombetas, Oriximiná, Pará. Boletim do Museu Paraense Emílio Goeldi Ciências Naturais. Belém, v.6, n.3, p.273293. 2011.

SEPLAN/MT SECRETARIA DE PLANEJAMENTO E COORDENACCÃO GERAL/GOVERNO DO ESTADO DO MATO GROSSO. Atlas de Mato Grosso. Cuiabá: Entrelinhas, 2011.96 p. 
SILVA, F. C. (ed.). Manual de análises químicas, plantas e fertilizantes. 2. ed. rev. aum. Brasília: Embrapa Informação Tecnológica, 2009. 627 p.

WADT, L. H. O.; SOUZA, J. M. L. Características da espécie e relações com o ambiente. In: SOUZA, J. M. L.; CARTAXO, C. M. B. C. C.; LEITE, F. M. N.; SANTOS, J. C. dos; WADT, L. H de O.; GONÇALVES, L. de M. P. B.; MAUÉS, M. M.; ÁlVARES, V. de S. Árvore do conhecimento: Castanha do Brasil. Disponível em: $<$ http://www.agencia.cnptia.embrapa.br/gestor/castanhadobrasil/arvore/CONT000fzfy7i8602wx5ok0cpoo6a08db1x h.html>. Acesso em 18 de outubro de 2016. 